\title{
Spoken language acquisition in children with prelingual hearing loss: A review of their morphosyntactic abilities at the sentence level
}

\author{
Analí R. TABOH ${ }^{1,2,3}$, Diego E. SHALOM ${ }^{1,3}$, Carolina A. GATTEI ${ }^{1,3,4}$ \\ 1'Departamento de Física, FCEyN, Universidad de Buenos Aires and IFIBA, CONICET \\ ${ }^{2}$ Facultad de Filosofía y Letras, Universidad de Buenos Aires \\ ${ }^{3}$ Laboratorio de Neurociencia, Universidad Torcuato di Tella \\ ${ }^{4}$ Pontificia Universidad Católica Argentina
}

Version date: August 23, 2021

Contact:

anali.taboh@conicet.gov.ar (Analí Taboh)

\section{Abstract}

The language development of children with hearing impairment who access spoken language through hearing devices $(\mathrm{CHI})$ usually lags behind that of children with typical development. In order to improve therapeutic and educational practices for these children, it is important to understand which specific aspects of language represent difficulties for them. This work reviews the evidence on $\mathrm{CHI}$ 's morphosyntactic abilities at the sentence level by focusing on their comprehension and production of specific types of structures: simple sentences, topicalized sentences, passives, sentences with relative clauses, and wh-questions. It also reviews demographic, clinical, and cognitive factors that introduce variability in CHI's performance, as well as different accounts of their difficulties at the sentence level.

Keywords: children with hearing impairment, sentence comprehension and production, complex sentences, morphosyntax. 


\section{Introduction}

Prelingual hearing loss (i.e. hearing loss with onset previous or simultaneous to language acquisition, typically up to age three; $\mathrm{HL}$ ) has an impact not only on the acquisition of spoken language but also on academic, emotional, and social development (Dammeyer, 2010; Qi and Mitchell, 2012). In the long term, it affects people's opportunities for employment and social integration. Even though assistive devices such as hearing aids (HAs) and cochlear implants (Cls) improve hearing considerably, children with hearing impairment acquiring spoken language (CHI) usually do not achieve the same level of language development as children with typical development (CTD). Several studies have reported this for children with different degrees of HL and who speak different languages (Tomblin, Barker, Spencer, Zhang, and Gantz, 2005; Delage, 2008; Geers, Moog, Biedenstein, Brenner, and Hayes, 2009; Inscoe, Odell, Archbold, and Nikolopoulos, 2009; Niparko et al., 2010; Caselli, Rinaldi, Varuzza, Giuliani, and Burdod, 2012; Nittrouer, Sansom, Low, Rice, and Caldwell-Tarr, 2014; Soleymani, Mahmoodabadi, and Nouri, 2016). It is crucial to research which aspects of language are affected when a child with HL acquires spoken language, the reasons behind these limitations, and which factors influence the process. This research will then allow to improve and fine-tune therapeutic and educational practices so that children with $\mathrm{HL}$ can have better language attainment and, thus, the same opportunities as their peers with normal hearing.

In particular, the aim of this work is to provide a comprehensive review of what has been reported regarding the morphosyntactic abilities of $\mathrm{CHI}$ at the sentence level. Rather than providing an overall view, we wish to pinpoint which specific aspects of morphosyntax present difficulties for $\mathrm{CHI}$. The review is organized as follows: We first review the evidence on CHI's comprehension and production of sentences with different structures. Next we describe possible factors that introduce variability in CHI's performance. We then review the evidence on how different demographic, clinical, and cognitive factors are related to $\mathrm{CHI}$ 's performance. Finally, we present and discuss possible accounts of CHI's difficulties in sentence comprehension and production.

In this review, we have included those publications that meet the following criteria: (i) they include $\mathrm{CHI}$ whose first language is an oral language; (ii) they evaluate the acquisition, comprehension and/or production of sentences in spoken language in $\mathrm{CHI}$; (iii) they present separate results for different syntactic structures. Because we focus on $\mathrm{CHI}$ 's morphosyntactic abilities 
in spoken language, and given that, as mentioned above, access to sound is much improved by hearing devices, we have excluded from this review those studies which do not indicate whether the $\mathrm{CHI}$ used hearing devices. See Table A1 in Appendix A for the list of included and excluded studies.

Studies targeting this population vary widely in their experimental designs. One way in which they differ is in the use of standardized tests, experiments designed to evaluate specific structures, or speech samples. At the sentence level, there is vast evidence that $\mathrm{CHI}$ perform below CTD on standardized tests (Young and Killen, 2002; Geers, Nicholas, and Sedey, 2003; Nikolopoulos, Dyar, Archbold, and O'Donoghue, 2004; Schorr, Roth, and Fox, 2008; Geers et al., 2009; Boons et al., 2013; Mandal, Kumar, and Roy, 2016; Soleymani et al., 2016, but see Briscoe, Bishop, and Norbury, 2001; Norbury, Bishop, and Briscoe, 2001; Hansson, Forsberg, Löfqvist, Mäki-Torkko, and Sahlén, 2004; Halliday and Bishop, 2005; Duchesne, Sutton, and Bergeron, 2009; Halliday, Tuomainen, and Rosen, 2017). Indeed, standardized tests like the Test for Auditory Comprehension of Language (Woolfolk-Carrow, 1999), the Reynell Developmental Language Scale (Reynell \& Gruber, 1990), the Clinical Evaluation of Language Fundamentals (Semel, Wiig, and Secord, 1995; Semel-Mintz, Wiig, and Secord, 2003), and the Test for Reception of Grammar (Bishop, 2003) have been commonly used for evaluating morphosyntactic performance in these children. The main limitation of standardized tests like these is that they assess a range of structures but do not analyze each of them separately. As a consequence, while they provide a general picture of morphosyntactic abilities, they do not allow to identify which specific structures present difficulties for $\mathrm{CHI}$. For this reason, in this work we will not include studies using this type of assessment; instead, we will include studies using experiments or speech samples to evaluate specific structures. We will focus on the following: simple sentences, topicalized sentences, passives, sentences with relative clauses, and open questions or wh-questions (see examples of each structure in Table 1).

Another way in which studies targeting $\mathrm{CHI}$ differ is how experimental groups are formed. The performance of $\mathrm{CHI}$ is compared to that of CTD matched (either at the group or the individual level) on chronological age (Boons et al., 2013; Halliday et al., 2017), hearing age (i.e. time since an adequate hearing device has been received; Caselli et al., 2012; Schouwenaars, Finke, Hendriks, and Ruigendijk, 2019), language level (typically measured in mean length of utterance or vocabulary; Volpato, 2010; Volpato and Vernice, 2014), school grade (Nittrouer et al., 2014) or nonverbal cognitive ability (Nittrouer et al., 2014). Also, groups of CHI vary in how 
Table 1: Structures this review focuses on and examples of each

\begin{tabular}{ll}
\hline Structure & Example \\
\hline Simple active sentences & The dog is chasing the cat. \\
Topicalized sentences & The cat, the dog is chasing. \\
Passives sentences & The cat is being chased by the dog. \\
Sentences with relative clauses & The dog that is chasing the cat is white. \\
& The cat that the dog is chasing is white. \\
& Who is chasing the cat? \\
Wh-questions & Who is the dog chasing? \\
& Which dog is chasing the cat? \\
& Which cat is the dog chasing?
\end{tabular}

homogeneous or heterogeneous they are. For example, while the chronological age range of the CHI group in Caselli et al. (2012) is 3;8 to 5;5, Friedmann and Haddad-Hanna (2014) include $\mathrm{CHI}$ aged 9-21 years; whereas the $\mathrm{CHI}$ in Geers et al. (2003) range in hearing age from 4 to 6 years, the $\mathrm{CHI}$ in DeLuca (2015) range from 4 to 10. Also, while Ruigendijk and Friedmann (2017) test CHI with moderate to profound HL, Penke and Wimmer (2018) test CHI with mild to severe HL, and Volpato and Vernice (2014) focus on CHI with profound HL; and whereas Lee, Sung, and Sim (2018) report on CHI with Cls, Werfel, Reynolds, Hudgins, Castaldo, and Lund (2021) include some CHI with HAs and others with Cls. Careful examination of these variables is crucial for accounting for linguistic performance in this population. In the following sections we review the evidence presented by those studies that have focused on how $\mathrm{CHI}$ with different degrees of $\mathrm{HL}$ and who use different languages comprehend and produce specific types of syntactic structures.

\section{Simple sentences}

Studies that include simple active sentences with canonical word order as part of their stimuli have generally found that groups of $\mathrm{CHI}$ across the range of $\mathrm{HL}$ perform at ceiling on these structures, both in comprehension (mild to moderate HL: Norbury, Bishop, and Briscoe, 2002 for English; moderate to severe HL: Friedmann, Novogrodsky, Szterman, and Preminger, 2008 for 
Hebrew; moderate to profound HL: Friedmann and Szterman, 2006; Friedmann, Rizzi, and Belletti, 2016 for Hebrew; Friedmann and Haddad-Hanna, 2014 for Palestinian Arabic; Ruigendijk and Friedmann, 2017 for German; degree of HL not stated: Fujiyoshi et al., 2012 for Japanese; Lee et al., 2018 for Korean) and in production (mild to moderate HL: Delage, 2008 for French; moderate to severe HL: Friedmann and Szterman, 2011 for Hebrew; moderate to profound HL: Ruigendijk and Friedmann, 2017 for German). Nevertheless, some studies have found differences between $\mathrm{CHI}$ and CTD in performance in these structures. Ruigendijk and Friedmann (2017) found that German-speaking CHI with moderate to profound HL aged 9-13 years repeated simple SVO sentences with over $90 \%$ accuracy (as a group), but still significantly below a group of age-matched CTD; the authors attributed this difference to the CTD performing at $100 \%$ accuracy. Also in repetition, Caselli et al. (2012) reported that Italian-speaking CHI with profound HL aged 3-5 years were significantly less accurate than CTD matched on chronological age, but not when compared to younger CTD matched on hearing age ${ }^{1}$. Novogrodsky, Meir, and Michael, 2018 analyzed the repetition of short simple sentences with nominal, unergative, SV unaccusative, and VS unaccusative structure in Hebrew-speaking $\mathrm{CHI}$ with mild to profound $\mathrm{HL}$ aged 2-3 years and age-matched CTD, and they found a marginal interaction between group and sentence structure. Regarding the age of acquisition of simple sentences, Fujiyoshi et al. (2012) reported that Japanese-speaking CHI reached levels of comprehension above $80 \%$ at age 6 and above $90 \%$ at age 8 , while CTD were already over $90 \%$ accurate at least as young as 5 years (the study did not include children younger than 5 years). Analyses of individual performance also indicate that CHI's comprehension and production of simple sentences are not always entirely preserved. Across different experiments, Ruigendijk and Friedmann (2017) showed that $10-20 \%$ of the $\mathrm{CHI}$ performed significantly below the control groups.

While simple active sentences with canonical word order are usually preserved in $\mathrm{CHI}$, there is extensive evidence that more complex sentences pose considerable difficulties for this population. Below, we summarize the findings on several complex structures and briefly discuss possible lines of future investigation.

\footnotetext{
${ }^{1}$ However, it should be noted that, apart from simple SVO sentences, the repetition task in this study included SV sentences with unergative verbs and SV sentences where the verb was transitive but the object was omitted (though still predictable, e.g. with verbs like 'iron').
} 


\section{Topicalized sentences}

The acquisition of sentences with topicalized object has been studied in $\mathrm{CHI}$ in comprehension and repetition. Several works have examined two different topicalization structures in Hebrew: OSV structures, which only differ from the canonical SVO order in that the object is in first position, and preserve the SV order, and OVS, where the position of each constituent relative to the others is different than in the canonical order (Friedmann and Szterman, 2006; Friedmann et al., 2008; Friedmann and Szterman, 2011; Friedmann et al., 2016). Friedmann and Szterman (2006) found that CHI with moderate to profound HL comprehended topicalized OSV structures similarly to CTD approximately 2.5 years younger - and at ceiling - but topicalized OVS structures significantly worse, with 9 of the $20 \mathrm{CHI}$ performing at chance. Similarly, Friedmann et al. (2008) found that CHI with moderate to severe HL comprehended OVS topicalization structures significantly below younger CTD. Accuracy in the comprehension of this type of sentences ranged from 59\% (in Friedmann et al., 2008) to less than 70\% (in Friedmann and Szterman, 2006). It would seem from these results that OSV topicalization is easier for Hebrew-speaking CHI than OVS topicalization. However, Friedmann and Szterman (2006) suggested that CHI's ceiling performance on OSV sentences might not have always been the result of a correct syntactic representation, because when hearing these sentences they often repeated the SV part and then pointed, within the correct picture, to the agent of the action, not to the theme. As for OVS structures, Friedmann et al. (2016) argued that the fact that $\mathrm{CHI}$ did not present systematic below-chance performance (only 2 out of $18 \mathrm{CHI}$ in their study performed below-chance) indicates that they did not interpret these sentences as SVO, which suggests that they were sensitive to the case information provided by the object marker, but could not use it to build the correct interpretation.

For German, Ruigendijk and Friedmann (2017) (experiment 2) reported that CHI with moderate to profound $\mathrm{HL}$ showed comprehension of OVS topicalized sentences at chance level, and significantly worse than CTD aged as the youngest CHI. Fujiyoshi et al. (2012) compared the age of acquisition of OSV structures (which they refer to as 'reversed word order objectagent-verb, OAV') in Japanese-speaking CHI and CTD, with a sentence-picture matching task. A child was considered to have acquired a given structure when she selected the correct picture

for at least three of the four sentences presented for that structure. The authors found that OSV structures were acquired later by $\mathrm{CHI}$ ( $8 \%$ of 5 -year-olds, $23.1 \%$ of 6 -year-olds, and $47.1 \%$ of 
8-year-olds) than by CTD (52.3\% of 5-year-olds, $67.9 \%$ of 6 -year-olds, and $82.1 \%$ of 8 -year-olds).

In repetition tasks, to the best of our knowledge only OSV structures have been tested. Hebrew-speaking $\mathrm{CHI}$ with moderate to severe $\mathrm{HL}$ repeated these structures with $61 \%$ accuracy, over 30\% less than the younger CTD (Friedmann \& Szterman, 2011). While there is convergent evidence that sentences with topicalized object are challenging for $\mathrm{CHI}$, further investigation is needed to clarify whether this is true only for those with OVS order or also for sentences with OSV order.

\section{Passive sentences}

Most studies on the comprehension and production of passive sentences by $\mathrm{CHI}$ have provided evidence of good performance, even if differences with CTD have been observed. Norbury et al. (2002) found that English-speaking CHI with mild to moderate HL performed similarly to age-matched CTD in a sentence-picture matching task including full passives, short progressive passives, and short ambiguous passives. Ruigendijk and Friedmann (2017) found similar results, also with a sentence-picture matching task, for German-speaking $\mathrm{CHI}$ with moderate to profound $\mathrm{HL}$. In a repetition task, these children showed group performance above $90 \%$ but still significantly below age-matched CTD, which the authors attributed to the ceiling performance of CTD. It should be noted, however, that the children who participated in the repetition tasks in Ruigendijk and Friedmann, 2017 had passed a simple sentence repetition screening test. Only those who made errors in no more than one sentence, including omission or substitution of determiners (which in German are marked by case), were included. Given that there is evidence that German-speaking CHI omit and substitute determiners more often than CTD matched on mean length of utterance (Szagun, 2004), the $\mathrm{CHI}$ in Ruigendijk and Friedmann (2017) might not be representative of the population.

Lee et al. (2018) reported that Korean-speaking CHI with Cls comprehended passive sentences with $16 \%$ less accuracy than age-matched CTD. The authors also reported that, in a logistic regression in which group was entered as the dependent variable and active and passive sentence scores were entered as independent variables, passive (but not active) sentence scores were significantly associated with the identification of $\mathrm{CHI}$ among all children included in the study, i.e., children with lower passive sentence scores were more likely to be classified as $\mathrm{CHI}$. This evidence suggests that $\mathrm{CHI}$ comprehend and produce passive sentences relatively 
well. There are, however, some cases of poor performance among the $\mathrm{CHI}$ included in these studies: 2 out of the $19 \mathrm{CHI}$ in Ruigendijk and Friedmann (2017) performed at or below chance in the sentence-picture matching task, and accuracy in Lee et al. (2018) ranged from 10 to 100\% (while accuracy in CTD ranged from 70 to 100\%).

Nevertheless, one study found a considerable delay in CHI's acquisition of passive sentences. Fujiyoshi et al. (2012) found that Japanese-speaking CHI acquired these structures much later than CTD. The CTD who comprehended correctly at least three of the four sentences in passive voice included in the test were $22.7 \%$ of 5 -year-olds, $64.3 \%$ of 6 -year-olds, and $75.0 \%$ of 8-year-olds, whereas in the $\mathrm{CHI}$ group they were $8.0 \%$ of 5 -year-olds, $0 \%$ of 6 -yearolds, $42.9 \%$ of 7 -year-olds, $35.3 \%$ of 8 -year-olds, $53.8 \%$ of 9 -year-olds, $41.7 \%$ of 10 -year-olds, $63.6 \%$ of 11 -year-olds, and $75.0 \%$ of 12 -year-olds. It is interesting to note that passive sentences were the last structure to be acquired by CTD, but not by $\mathrm{CHI}$, who acquired sentences with relative clauses last.

As can be seen, the number of studies that have examined the comprehension and production of passive sentences in groups of $\mathrm{CHI}$ with access to modern hearing devices and treatment are very scarce. In many languages, including English and German, the passive voice is formed with an auxiliary verb and presents the agent with a prepositional phrase, all of which might make the structure more easily identifiable than other types of sentences. More studies in different languages and with $\mathrm{CHI}$ with varying degrees of $\mathrm{HL}$ are needed to elucidate whether these structures are problematic. In particular, future research should look into languages with alternative markers of passive voice. Analyzing whether the performance with passive sentences is related to how the passive construction is formed in each language might provide insight into CHI's language development.

\section{Sentences with relative clauses}

Davis and Blasdell (1975) examined the comprehension of subject relative clauses in Englishspeaking $\mathrm{CHI}$ with mild to moderate $\mathrm{HL}$ aged 6-9 years. Their sentence-picture matching task included four pictures that represented different simple sentences: the main sentence (the correct answer, which likely showed comprehension of both clauses), the embedded clause, the object of the relative clause performing a new action to the object of the main clause, and the relative clause with thematic role reversal. While both the $\mathrm{CHI}$ and age-matched CTD 
selected the correct picture more often than the other three, the $\mathrm{CHI}$ selected it significantly less often than the CTD, and the rate of correct answers was not influenced by age or degree of $\mathrm{HL}$. The $\mathrm{CHI}$ also differed from the controls in their pattern of errors: they chose the two pictures that did not represent any part of the orally-presented sentence more often.

Volpato and colleagues (Volpato, 2010, 2020; Volpato \& Vernice, 2014) have examined the comprehension and production of relative clauses in Italian-speaking $\mathrm{CHI}$ with profound $\mathrm{HL}$. They found the same gradient of difficulty present in typical development (i.e., subject relatives are easier than object relatives and object relatives with preverbal embedded subject are easier than object relatives with postverbal embedded subject). While the $\mathrm{CHI}$ performed overall significantly below CTD in both comprehension and production, the patterns for each type of relative clause differed in the two tasks. $\mathrm{CHI}$ aged 7-10 years comprehended subject relatives and a subtype of object relatives with preverbal subject similarly to younger CTD matched on morphosyntactic abilities (Volpato, 2010) and to CTD matched on age (Volpato, 2020), but they comprehended another subtype of object relatives with preverbal subject and object relatives with postverbal subject significantly worse than both CTD groups. These studies also looked into how the pattern of comprehension of object relatives with preverbal subject differed between CTD and $\mathrm{CHI}$ according to whether the number features between two noun phrases matched or not. CHI were significantly less accurate than younger and same-age CTD in sentences with this type of relatives in the mismatch condition, but not different from either CTD group in the match condition. Additionally, the $\mathrm{CHI}$ showed a different gradient of difficulty among number match and mismatch conditions than both CTD groups: while the CTD were more accurate in the mismatch condition, the $\mathrm{CHI}$ were more accurate in the match condition. The author proposed that $\mathrm{CHI}$ are less sensitive to number features and it is therefore more difficult for them to exploit the number cues on the verb in order to comprehend the sentence.

Volpato and Vernice (2014) studied relative clause production with an elicitation task in which children were required to express which of two characters they preferred. They found that $\mathrm{CHI}$ produced fewer correct subject and object relative clauses than a group of age-matched CTD, a group of younger CTD matched on morphosyntactic abilities, and another group of younger CTD matched on hearing age. The $\mathrm{CHI}$ also differed from the CTD on the types of sentences they produced. Whereas Italian-speaking CTD usually produce more object relatives at first and then shift to passive relatives at later stages of their development, $\mathrm{CHI}$ as a group were at an intermediate position between the younger and age-matched CTD, producing fewer ob- 
ject relatives and more passive relatives than the former, and more object relatives and less passive relatives than the latter. At the individual level, however, some $\mathrm{CHI}$ performed similarly to same-age CTD, others similarly to younger CTD, and yet others adopted strategies which are attested in younger CTD but never or rarely in CTD of their age.

In Hebrew- and Palestinian Arabic-speaking CHI, Friedmann and colleagues (Friedmann and Szterman, 2006; Friedmann et al., 2008; Friedmann and Haddad-Hanna, 2014) found the same gradient of difficulty in relative clause comprehension as Volpato and colleagues found in Italian-speaking children: subject relatives were easier than object relatives and (in the case of Palestinian Arabic) object relatives with preverbal subject were easier than object relatives with postverbal subject. When compared to younger CTD who performed at or near ceiling in all types of relatives, both groups of $\mathrm{CHI}$ had impaired comprehension of object relatives. However, Friedmann et al. (2008) found that the performance of Hebrew-speaking CHI differed considerably between object relatives with a gap and object relatives with a resumptive pronoun (which is optional in the object position in Hebrew): an additional test including 8 of the $\mathrm{CHI}$ in their study revealed that the comprehension of all but one of them was between 95 and $100 \%$ accurate for object relatives with a resumptive pronoun. Contrary to Hebrew, in Palestinian Arabic the presence of the resumptive pronoun, which is obligatory in object relatives, did not facilitate comprehension. Friedmann and Costa (2011) proposed that this difference can be explained by the different status of the resumptive pronoun in each language: whereas in Hebrew it is a strong pronoun, and so can be assumed to be inserted post-syntactically, in Palestinian Arabic it is a clitic, and thus the result of a derivation, so $\mathrm{CHI}$ cannot rely on it to interpret wh-movement. Apart from the difficulty with object relatives, common to both Hebrew- and Palestinian Arabic-speaking $\mathrm{CHI}$, the latter were significantly more impaired in object relatives with postverbal subject than with preverbal subject.

Interestingly, while both groups showed relatively good comprehension of subject relatives, the Hebrew-speaking CHI (Friedmann \& Szterman, 2006; Friedmann et al., 2008) performed no differently from the younger CTD controls, but the Palestinian Arabic-speaking CHI were significantly below in Friedmann and Haddad-Hanna (2014), even though in all these studies the CTD groups were on average 2 or more years younger. The Hebrew-speaking CHI in Friedmann et al. (2008), however, did perform significantly below a group of age-matched CTD. 
Friedmann and colleagues (Friedmann \& Szterman, 2006; Friedmann et al., 2008) also examined the production of relative clauses in Hebrew-speaking $\mathrm{CHI}$ with moderate to profound $\mathrm{HL}$. In two elicitation tasks using picture preference and picture description, the $\mathrm{CHI}$ had difficulties producing both subject and object relatives, but did much worse on the latter. In many cases, instead of producing object relatives, they produced subject relatives, sentences without relative clauses or ungrammatical sentences. Whenever they produced object relatives, they tended to include a resumptive pronoun in object position, which is a way of avoiding movement, since the resumptive pronoun fills the position that would correspond to the gap. The authors pointed out that, while object relatives with resumptive pronouns are grammatical in Hebrew, they are characteristic of much younger children than the $\mathrm{CHI}$ included in their study. The $\mathrm{CHI}$ sometimes (though much less often) produced resumptive pronouns in subject relatives too, which are ungrammatical in Hebrew and were almost never produced by the CTD. They also doubled the noun phrase in both subject and object relatives, which is also ungrammatical and never produced by CTD.

Ruigendijk and Friedmann (2017) reported that German-speaking CHI with moderate to profound HL comprehended subject and object relatives significantly worse than CTD aged as the younger $\mathrm{CHI}$ and showed greater difficulties in object relatives, in which they performed at chance level. These authors also examined the production of subject relatives with a repetition task and found a significant difference between groups for center-embedded subject relatives but not for right-branching ones.

Delage (2008) (also reported in Tuller and Delage, 2014) studied the morphosyntactic abilities of French-speaking $\mathrm{CHI}$ with mild to moderate $\mathrm{HL}$ employing different methodologies, including a standardized battery, elicitation tasks and speech samples. The analysis of spontaneous speech samples taken approximately two years apart from each other showed that, while at age 6-11 years old $\mathrm{CHI}$ produced significantly fewer relative clauses than age-matched CTD, this was not the case at age 7-13. In a task that elicited the production of subject and object relative clauses, Delage found that $\mathrm{CHI}$ aged 7-11 produced significantly fewer subject relatives than a group of 6-year-old CTD and than $\mathrm{CHI}$ aged 11-13, and that the latter (but not the youngest $\mathrm{CHI}$ ) produced significantly fewer object relatives than the 6-year-old CTD. However, the author pointed out that the low performance of the youngest $\mathrm{CHI}$ on subject relatives was probably due to the very poor performance of three children in that group. As regards object relatives, there was a general tendency to produce causative passives or passive subject 
relatives instead, which are also appropriate responses to the task. This tendency was high in 6-year-old CTD and higher in the eldest CHI (75 and 92\% of non-object relative clauses, respectively). This task, thus, did not allow to draw conclusions about CHI's ability to produce object relatives.

Werfel et al. (2021) also examined the production of relatives clauses in the spontaneous speech of CHI. Their analyses included subject, object, oblique, adjunct, and headless relatives. The speech samples of a group of English-speaking 4-year-old CHI was compared to those of a group of same-age CTD and a group of CTD matched on mean length of utterance measured in morphemes. While the $\mathrm{CHI}$ did not differ significantly from either CTD group in the number of correct relative clauses produced for any of the five types of relatives analyzed, they did produce a lower percent of correct subject relatives than both CTD groups. According to the authors, this measure indicated that, when attempting to produce subject relatives, the $\mathrm{CHI}$ made errors more often than the CTD. It is interesting that this was the case for subject but not for object relatives, given the usual finding, mentioned above, that object relatives present more difficulties than subject relatives.

As regards the age of acquisition, Fujiyoshi et al. (2012) found that Japanese-speaking CHI acquired sentences with both subject and object relative clauses much later than CTD. Over $70 \%$ of the 6-year-old CTD and over $90 \%$ of the 8 -year-old CTD comprehended correctly at least three of the four subject relatives included in the test. In contrast, only around $30 \%$ of the 8year-old $\mathrm{CHI}$ and $73 \%$ of the 11 -year-old $\mathrm{CHI}$ met this criterion. In the case of object relatives, more than $80 \%$ of the 6 -year-old CTD and almost $90 \%$ of the 8 -year-old CTD comprehended at least three out of four sentences correctly, whilst only around 50\% of the 8-, 9-, 10-, and 11-year-old CHI met the criterion.

As can be gathered from this section, sentences with relative clauses have received a lot of attention from researchers studying the spoken language abilities of $\mathrm{CHI}$. Almost all studies report impaired comprehension and production of object relatives in $\mathrm{CHI}$, even when compared to younger CTD. In languages that allow both preverbal and postverbal object relatives, the latter are more affected. As for subject relatives, the evidence is less straight-forward, with some studies reporting that comprehension and production of these structures is relatively spared, and others that it is worse than that of younger CTD. Furthermore, some studies showed that the error patterns of $\mathrm{CHI}$ in tasks of both comprehension and production of relative clauses 
differ from those observed in CTD.

\section{Wh-questions}

Wh-questions have also received considerable attention in the study of language abilities of $\mathrm{CHI}$. Wh-question comprehension has been most frequently assessed with point-in-picture tasks, in which the participant is shown a picture of three characters interacting, where two are similar and one is different, e.g. a mother combing a girl on her left and being combed by another girl on her right, a boy being sprayed by an elephant on his left and spraying another elephant on his right. The participant is then asked a question, such as Which elephant is the boy spraying?, and has to answer by pointing at one of the characters in the picture.

Friedmann and colleagues used this task to study question comprehension in Hebrew- and Palestinian Arabic-speaking CHI. Friedmann and Szterman (2011) reported that a small group of Hebrew-speaking $\mathrm{CHI}$ with moderate to severe $\mathrm{HL}$ aged 9-12 comprehended subject and object who-questions similarly to a group of CTD on average 2 years younger, but they comprehended subject and object which-questions significantly worse. Among these four types of questions, the most difficult ones for $\mathrm{CHI}$ were object which-questions, on which all $11 \mathrm{CHI}$ in the sample performed below the CTD group. A similar pattern of results for the comprehension of subject and object which-questions was reported in Friedmann and Haddad-Hanna (2014) for Palestinian Arabic-speaking $\mathrm{CHI}$ and adolescents with moderate to profound $\mathrm{HL}$ aged 9-21 (mean age 13;7). This group of $\mathrm{CHI}$ performed significantly below a group of much younger CTD aged 6-8 on subject and object questions, the latter both with preverbal and postverbal subject. They also displayed the same gradient of difficulty found for sentences with relative clauses and topicalized sentences: object questions were comprehended more poorly than subject questions, and within object questions those with postverbal subject were harder than those with preverbal subject.

Friedmann and Szterman (2011) also investigated wh-question production in Hebrew-speaking $\mathrm{CHI}$ with moderate to severe $\mathrm{HL}$ aged 9-12. In one experiment they compared their elicited production of who-questions with that of CTD two years younger. In this elicitation task, the children saw a picture in which one character was performing an action on another but one of them was concealed; the children had to ask a question for which the answer would be the concealed character. In contrast to what the authors found for who-question comprehension, 
the $\mathrm{CHI}$ produced significantly fewer subject and object who-questions than the CTD on average 2 years younger. Their production of subject questions was, however, significantly better than their production of object questions. In another experiment, Friedmann and Szterman compared the repetition of which-questions in the same group of $\mathrm{CHI}$ and a group of 5-yearold CTD. They found the same pattern of results previously found for the comprehension of this type of questions and for the elicited production of who-questions, even though the age difference with the CTD group who participated in the repetition task was much larger.

Two studies investigated the comprehension of short subject and object who-questions in German-speaking CHI with mild to severe $\mathrm{HL}$ aged 3 to 4 years (Wimmer, Rothweiler, and Penke, 2017; Penke and Wimmer, 2018). They employed a questions-after-story task in which the children were shown a picture of two people interacting, then heard a short story consisting of three sentences, and finally had to answer a question about the picture by pointing to the corresponding person in it. Both studies report that the $\mathrm{CHI}$ were overall significantly less accurate than age-matched CTD. When looking at group differences in each question type, the results of these studies differed: Wimmer et al. (2017) found no significant interaction between hearing status and question type, but Penke and Wimmer (2018) found that the two groups differed significantly on object questions and marginally on subject questions. Regarding the comparison between question types, the two studies report that both groups comprehended subject who-questions better than object who-questions; however, this asymmetry was more pronounced in the $\mathrm{CHI}$ group (Wimmer et al., 2017) and not significant in the CTD group (Penke \& Wimmer, 2018).

In relation to the stages of acquisition of these structures, Wimmer et al. (2017) found that, with object questions, $\mathrm{CHI}$ aged 3 performed at chance level, while $\mathrm{CHI}$ aged 4 performed similarly to 3-year-old CTD. Moreover, the authors observed three different performance patterns present - with different proportions - in both groups of children: chance performance with both subject and object who-questions, above chance performance with subject questions, and above chance performance with both types of who-questions. The latter, more advanced pattern was reached at age 3 by most CTD (73\% at age 3, 92\% at age 4) but only at age 4 by most $\mathrm{CHI}(22 \%$ at age $3,83 \%$ at age 4$)$. Considering also that there was no significant interaction between hearing status and age, the authors suggested that the $\mathrm{CHI}$ showed the same stages of acquisition as the CTD, but delayed. Penke and Wimmer (2018) tested 10 children in their $\mathrm{CHI}$ group again when they were 6-8 years old. For this subgroup of $\mathrm{CHI}$, mean accuracy 
at first testing was $92 \%$ and $82.8 \%$ for subject and object who-questions, respectively, and did not differ significantly from the rest of the group. At retest, their mean accuracy with both types of who-questions had improved to $99 \%$ and all 10 children had overall accuracy levels of $95 \%$ or higher.

Ruigendijk and Friedmann (2017) examined the comprehension and repetition of subject and object who- and which-questions in German-speaking $\mathrm{CHI}$ with moderate to profound $\mathrm{HL}$ aged 9-13 years. In a point-in-picture task, $\mathrm{CHI}$ showed worse comprehension than CTD aged as the younger $\mathrm{CHI}$ for subject which-questions (significant difference) and object whichquestions (marginal difference, which the authors attributed to some CTD still having difficulties with this structure). While the CTD group performed above chance on all four types of questions, the $\mathrm{CHI}$ group did so on subject who- and which-questions and on object whoquestions, but they performed at chance level on object which-questions. In contrast to Penke and Wimmer (2018), in this study the subject/object asymmetry in comprehension was significant in both groups of children and with both types of wh-questions.

Ruigendijk and Friedmann (2017) also report on CHI's question repetition with two tasks: the first task included long subject and object who-questions (with an extra prepositional phrase) and short subject and object which-questions; the second one included long subject and object who- and which-questions. In the first repetition task, the $\mathrm{CHI}$ performed similarly to aged-matched CTD on both types of subject questions (i.e. long subject who-questions and short subject which-questions), and significantly below the CTD group on both types of object questions (long object who-questions and short object which-questions). In the second repetition task, the CTD group was not age-matched to the $\mathrm{CHI}$ but was aged as the younger $\mathrm{CHI}$; there were no significant differences between groups on any of the four types of long questions. The authors indicate that this result might be due to the CTD being younger and the sentences longer.

Another work on the comprehension of wh-questions by German-speaking $\mathrm{CHI}$ was carried out by Schouwenaars et al. (2019), who investigated not only how accurate these children's comprehension was but also how they processed these structures. A picture selection task with eye-tracking and assessing subject, object and passive which-questions was employed in a group of $\mathrm{CHI}$ who had severe to profound $\mathrm{HL}$ and were 7 to 12 years old. The study also examined whether performance varied when different cues were available for interpretation. 
In passive which-questions, the interpretation of the first noun phrase (NP) was always disambiguated by the verb in passive voice and the by-phrase. For subject and object whichquestions, there were three different disambiguation conditions: disambiguation by the case of the first NP which contained the wh-word, by verb agreement, or by both case and agreement. The results of the questions task reported on included only those children who showed good perception of case and agreement information in two screening tasks. Both in accuracy and gaze patterns, the $\mathrm{CHI}$ performed similarly to a group of CTD matched on hearing age (i.e. aged 7 to 10) on subject and passive questions but differently on object questions. With subject and passive questions both CHI and CTD performed at ceiling and looked initially more at the competitor and, then, more at the target. With object questions, both groups of children were less accurate, but $\mathrm{CHI}$ comprehended them significantly worse than CTD. Furthermore, CHI's looks towards the target increased later and less steeply than for CTD, which was interpreted by the authors as indicating that the $\mathrm{CHI}$ were slower in revising their initial agent-first interpretation of object questions. The type of disambiguation did not seem to have an effect on accuracy, but it did on gaze patterns: while the CTD showed an initial subject interpretation on object questions (seen in an initial preference for the competitor, agent-first picture) when they were disambiguated by agreement alone or by agreement and case, but not by case alone, $\mathrm{CHI}$ also showed an initial subject interpretation on object questions disambiguated by case, which are disambiguated earlier. However, the fact that looks towards the agent-first picture differed between subject and object questions before the onset of the verb indicates that the $\mathrm{CHI}$ did not completely ignore the early case cue.

DeLuca (2015) also investigated the gaze patterns during who- and which-question comprehension, in English-speaking $\mathrm{CHI}$ with Cls. In this eye-tracking study, $\mathrm{CHI}$ aged 7-11 years listened to a context sentence and a question, and had to answer by clicking on one of four pictures, each showing a different character. The questions included subject and object whoand which-questions with low and high memory load; questions with high memory load were made longer by adding adjectives in the NPs. Overall, the $\mathrm{CHI}$ were significantly less accurate in their responses than a group of age-matched CTD. In trials answered correctly, the $\mathrm{CHI}$ did not differ significantly from the CTD in their fixations to the target picture during the syntactic gap. However, in the $\mathrm{CHI}$ group the probability of fixating the target was smaller with object than with subject questions - although reported as a tendency. In trials answered incorrectly, gaze patterns during the gap did differ significantly between the two groups. For subject questions, 
both groups fixated more at the object, which suggests they were both reversing the thematic roles. When they were not looking at the object, the CTD fixated at the other three pictures in equal proportion, but the $\mathrm{CHI}$ looked more at the description foil (i.e., an unrelated character that shared one descriptive similarity with the target, for instance both were female or both were elderly people), followed by the target and then by the attribute-related foil to the target noun phrase (i.e. the same picture with the defining attribute changed). On incorrectly answered object questions, the CTD exhibited the highest proportion of fixations at the target, followed by the three foils with very similar proportions. In contrast, the $\mathrm{CHI}$ most often fixated the attribute-related object foil, followed by the subject, then the target picture and, finally, the description foil. It seems that, for incorrectly answered object questions, the CTD might have originally assigned thematic roles correctly even if they later failed to select the target picture; in the case of $\mathrm{CHI}$, for whom the highest competition was from the same noun phrase category as the target, incorrect responses might have resulted from working memory limitations. Indeed, the $\mathrm{CHI}$ performed more poorly than the CTD on a battery of working memory tasks that was administered as part of the same study.

Volpato and D'Ortenzio (2018) and D'Ortenzio and Volpato (2020) studied the production of subject and object who- and which-questions in Italian-speaking $\mathrm{CHI}$ with $\mathrm{Cls}$. Both studies employed the same type of elicitation task used by Friedmann and Szterman (2011) and included CHI of very similar ages: 7-13 and 7-12, respectively. Volpato and D'Ortenzio (2018) did not find significant differences between the $\mathrm{CHI}$ and a group of age-matched CTD in accuracy nor in the use of the different correct and incorrect answering strategies. In contrast, the $\mathrm{CHI}$ in D'Ortenzio and Volpato (2020) performed significantly below a group of age-matched CTD and another group of CTD matched on hearing age since HA fitting ${ }^{2}$ on object who-questions and subject and object which-questions; on subject who-questions, however, they performed at ceiling. The differences between the $\mathrm{CHI}$ and the two CTD groups were significant when considering all types of correct responses and only wh- $\mathrm{V}-\mathrm{N}$ target structures (i.e., who-verb-noun phrase for who-questions or which+noun phrase-verb-noun phrase for which-questions), but not when considering all the other correct structures together (e.g., with topicalized or omitted subject, passive questions, etc.). The $\mathrm{CHI}$ also produced significantly more ungrammatical

\footnotetext{
${ }^{2} \mathrm{CHI}$ are usually first fitted with $\mathrm{HAs}$ and, if these do not provide enough improvement, then implanted with Cls. Nonetheless, hearing age for $\mathrm{CHI}$ with $\mathrm{Cls}$ is generally calculated as the time since the first $\mathrm{Cl}$ activation, not since HA fitting, as was done in this case.
} 
or incomplete sentences than both CTD groups.

The different results found by these two studies might be related to the clinical characteristics of the CHI groups. All the CHI in D'Ortenzio and Volpato (2020) were diagnosed and started intervention before their first year of life, whereas for the CHI in Volpato and D'Ortenzio (2018) this happened later, between birth and the age of 3;6 years. In the latter study the authors do not provide information on the CHI's degree of hearing loss and, while we can assume it was severe or profound because they all had at least one $\mathrm{Cl}$, it is possible that these children were diagnosed later because their hearing loss was less severe and they had more residual hearing. If this was the case, it might explain why they performed similarly to controls and the $\mathrm{CHI}$ in D'Ortenzio and Volpato (2020) did not.

There is, in all, convergent evidence that wh-questions pose considerable difficulties for $\mathrm{CHI}$, both in comprehension and production. Differences between $\mathrm{CHI}$ and CTD have been observed not only in offline measures (accuracy) but also in online measures (gaze patterns). In general, the gradient of difficulty that emerges is that who-questions are easier than whichquestions and, within each type, object questions are harder, with object which-questions being the hardest of all. Furthermore, $\mathrm{CHI}$ are reported to produce more ungrammatical sentences than CTD. However, not all evidence points to trouble with the same types of whquestions. While some studies report no differences between $\mathrm{CHI}$ and age-matched CTD, others have found $\mathrm{CHI}$ to perform worse than even much younger groups of CTD. Further investigation is needed to understand why different studies obtained different results. In particular, future studies might gain insight from looking into the relation between wh-question comprehension and production and cognitive abilities such as working memory.

\section{Sources of variability}

If language acquisition in CTD is characterized by wide variability (Kidd \& Donnelly, 2020), language acquisition in hearing-impaired children is even more so. A long list of additional factors come into play: degree of $\mathrm{HL}$ and level of residual hearing; age at onset of $\mathrm{HL}$; cause of $\mathrm{HL}$; type of hearing device; duration of hearing device use; type, duration, and frequency of speech therapy; parental hearing status; mode of communication used at home and at the educational setting (see Tomblin et al., 2015 for CHI with mild to severe HL with HAs and Gillis, 2018 for a review focusing on $\mathrm{CHI}$ with $\mathrm{Cls}$ ). Authors usually account for these differences by 
providing precise descriptions of the $\mathrm{CHI}$ group and, often, also of each child. Additionally, many authors carry out individual analyses comparing the performance of each child in the $\mathrm{CHI}$ group to that of the control group and/or to chance level.

These analyses have revealed that, despite significant differences between $\mathrm{CHI}$ and CTD at the group level, some $\mathrm{CHI}$ perform well even in the most problematic structures. For example, in Delage (2008), 2 of the 14 French-speaking CHI aged 7-11 performed at ceiling on the production of object relatives in the elicitation task. In Ruigendijk and Friedmann (2017), 12 out of 19 German-speaking $\mathrm{CHI}$ showed comprehension similar to the age-matched control group on object relatives, 10 and 12 out of 16 on subject and object which-questions, respectively, and 10 out of 16 on topicalized sentences. Of the $15 \mathrm{CHI}$ who participated in the wh-question repetition task, those who performed similarly to age-matched CTD were 12 and 8 for long subject and object who-questions, respectively, and 14 and 10 for short subject and object which-questions, respectively. In Schouwenaars et al. (2019), 13 out of 21 German-speaking $\mathrm{CHI}$ interpreted object which-questions with accuracy levels of $70 \%$ and higher, and two of them reached $100 \%$.

As can be seen from these examples, group results often mask individual variability, which is why individual analyses are a good and necessary practice when studying this population.

In the section below, we briefly comment on different extralinguistic factors that could modulate individual performance of this group of children.

\section{Demographic, clinical and cognitive factors related to $\mathrm{CHI}$ 's sentence comprehension and production}

Some of the studies that looked into CHI's sentence comprehension and production by targeting specific structures (instead of overall performance on a range of diverse structures) have also explored the influence of various demographic and clinical factors on their performance. Among the demographic factors, age was found to correlate positively with the comprehension of sentences with subject relative clauses (Volpato, 2010) and of object who-questions (Penke \& Wimmer, 2018), and to be a significant predictor of which-question comprehension (Schouwenaars et al., 2019), but no correlation was found between age and overall relative clause comprehension (Davis and Blasdell, 1975; Friedmann and Haddad-Hanna, 2014), comprehension of object relative clauses with preverbal or postverbal subject (Volpato, 2010), 
production of relative clauses and rate of complex utterances (i.e. with one or more embedded clauses) in spontaneous speech (Delage, 2008), comprehension of which-questions and topicalization structures (Friedmann \& Haddad-Hanna, 2014), comprehension of subject whoquestions (Penke \& Wimmer, 2018), and eye fixations to the target picture at the syntactic gap during who- and which-question comprehension (DeLuca, 2015). Hearing age was also found to be a significant predictor of which-question comprehension, but it did not correlate with subject, object and overall who-question comprehension (Penke \& Wimmer, 2018).

Evidence inquiring the relation between sentence comprehension and production and clinical hearing loss-related variables (e.g. degree of aided and unaided hearing loss, age of HA fitting, age of implantation, type of hearing device, age of diagnosis, age of onset of intervention, length of speech therapy) shows mixed results (see Tables B1 and B2 in Appendix B). While most studies found no significant results, a few studies have shown significant correlation among these factors. For instance, Delage (2008) reported a negative correlation between the rate of complex utterances in spontaneous speech and the degree of unaided hearing loss. Children with more severe HL produced significantly fewer complex utterances. A positive correlation between the spontaneous production of relative clauses without a main clause (e.g. The girl who plays) and the length of speech therapy was also found. Longer $\mathrm{Cl}$ use was related to better production of subject relatives in Volpato and Vernice (2014) and longer use of HAs prior to cochlear implantation was related to better production of object which-questions in D'Ortenzio and Volpato (2020). Age at HA fitting correlated negatively with comprehension of object relatives and topicalization structures with OVS order (pooled together) in Friedmann and Szterman (2006), i.e. the younger the child was at HA fitting, the higher her chances for having average comprehension levels above 70\%. Additionally, having had HAs fitted before 8 months was significantly correlated with having more chances of good comprehension (average accuracy above 70\%). Age at HA fitting also correlated negatively with production of object who-questions in D'Ortenzio and Volpato (2020). Since the clinical factors mentioned here are related, e.g. earlier fitting with hearing devices results in longer hearing device use, further research is needed to shed light on which of them are actually influencing CHI's performance.

Apart from demographic and clinical factors, some studies have looked into cognitive factors (see Table B3 in Appendix B). Few of the studies reviewed here have analyzed the relation between sentence comprehension and production and nonverbal abilities: a positive correlation with relative clause production in spontaneous speech was reported in Delage (2008), 
but no significant correlations were found with who-question comprehension in Penke and Wimmer (2018). A cognitive factor that has recently received increasing attention is memory capacity, in particular short-term memory and working memory. Lee et al. (2018) reported that passive sentence comprehension was highly correlated to working memory capacity as measured by a composite score including forward and backward digit and word spans (all administered in their visual versions), and that working memory accounted for $27.1 \%$ of the variance in passive sentence comprehension scores. Higher forward digit span was related to better comprehension of object relatives with preverbal subject with number mismatch between the first and the second NPs and of object relatives with postverbal subject in Volpato (2020). In Volpato (2010), forward digit span was not significantly correlated with relative clause comprehension, but forward word span was. Neither Volpato (2020) nor Volpato (2010) found significant correlations with backward digit span. In contrast, Schouwenaars et al. (2019) did report that better object which-question comprehension was related to higher backward digit span, although the lack of an interaction with group indicates that this was the case for CTD too. Again, it is hard to draw conclusions from these results. Although there is an increasing amount of evidence of the importance of memory resources for CHI's language outcomes (Pisoni and Geers, 2000; Dillon, Cleary, Pisoni, and Carter, 2004; Harris et al., 2013), it is still not clear whether memory capacity is specifically associated to sentence comprehension and production.

\section{Accounts of CHI's difficulties in sentence comprehension and production}

Different explanations of CHI's morphosyntactic difficulties have been proposed, accounting for poor linguistic attainment either as a direct result of hearing loss or as an indirect result of other aspects of cognitive development. Here we briefly review four accounts that point, respectively, to perceptual limitations, insufficient exposure to language early in life, and impaired memory or impaired cognitive sequencing caused by insufficient exposure to sound early in life.

There is abundant evidence from various languages that $\mathrm{CHI}$ often omit or are less accurate than CTD in their use of verbal inflection, nominal inflection, agreement, determiners, pronouns, prepositions, and other grammatical morphemes (e.g. Szagun, 2000, 2004; Le Normand, Ouellet, and Cohen, 2003; Hammer, 2010; Guo, Spencer, and Tomblin, 2013; 
Koehlinger, Horne, and Moeller, 2013; Guasti et al., 2014; Sundström, Löfkvist, Lyxell, and Samuelsson, 2018; Werfel, 2018). Some authors (Szagun, 2000, 2004; Svirsky, Stallings, Lento, Ying, and Leonard, 2002; Caselli et al., 2012) have suggested that these difficulties are related to CHI's perceptual limitations. Since grammatical markers are often short, formed by high frequency sounds, and unstressed, they are perceptually less salient and thus harder to perceive. Trouble perceiving grammatical morphemes would have consequences for the acquisition of grammar and the comprehension and production of sentences. Support for the perceptual salience hypothesis has been provided, for instance, by Svirsky et al. (2002), who showed that the order of acquisition of noun plural, copula, and past tense in English-speaking CHI was different than in CTD and that perceptually more salient elements were acquired earlier. Szagun (2000) combined this perceptual salience hypothesis with the idea that CHI probably have difficulties with the temporal processing of auditory stimuli. She proposed that, because CHI have difficulties discriminating speech sounds, they might fail to process speech sufficiently and, as a result, focus on content words instead, missing crucial grammatical information. In contrast to simple sentences where the overall meaning can be conveyed by content words, missing grammatical cues (be it because of low perceptual salience or because of insufficient auditory processing) would be particularly serious in the case of sentences that involve complex structures, like those reviewed in this work.

While the perceptual salience account focuses on the auditory limitations that $\mathrm{CHI}$ may experience even after they have received proper hearing devices and language therapy, other accounts focus on the period during which $\mathrm{CHI}$ did not receive (sufficient) auditory input. On the one hand, several authors (Friedmann and Szterman, 2006; Delage and Tuller, 2007; Friedmann and Szterman, 2011; Friedmann and Haddad-Hanna, 2014; Ruigendijk and Friedmann, 2017) attribute CHI's morphosyntactic difficulties to the lack of sufficient exposure to natural language during a critical (Lenneberg, 1967) or sensitive period for language acquisition. Namely, this account posits that being exposed to restricted and impoverished input during early childhood as a result of hearing loss hinders the development of morphosyntactic ability in $\mathrm{CHI}$. In this account, exposure to language during the critical/sensitive period is viewed as a necessary, but not sufficient, condition for language development. However, it is still unclear the length of the critical/sensitive period and the exact type of linguistic input that is needed during said period for typical morphosyntactic development in general, and for the acquisition of complex sentences in particular (a similar concern is raised in Ruigendijk and 
Friedmann, 2017). Another open question is how the lack of adequate linguistic input leads to morphosyntactic deficit, i.e. which are the linguistic mechanisms or abilities that are altered, and how. In the case of $\mathrm{CHI}$ who are able to perceive morphosyntactic cues but fail to use them in comprehension of complex sentences, Schouwenaars et al. (2019) have proposed that insufficient quality and quantity of linguistic input during development may lead to less automatized, slower processing, which may contribute to CHI's morphosyntactic difficulties.

On the other hand, it has been proposed that it is not the lack of exposure to language, but the lack of exposure to auditory input in early childhood which indirectly causes CHI's morphosyntactic difficulties. Two different accounts of this indirect link have been put forward. The first one posits that CHI's morphosyntactic difficulties arise because of immature or atypically developed performance systems, which are a consequence of hearing loss during early development (Delage, 2008; Tuller and Delage, 2014). Due to degraded auditory input, infants with hearing loss would need to allocate more attentional resources to sound processing than CTD, leaving fewer resources for other cognitive processes such as short-term memory and working memory; as a consequence, these performance systems would not mature normally. Since linguistic structures of high computational complexity like the sentences mentioned in this work put high demands on working memory, $\mathrm{CHI}$ would encounter difficulties in processing and acquiring them, leading to their morphosyntactic difficulties.

The other account of the indirect link between hearing loss and morphosyntactic difficulties is the auditory scaffolding hypothesis (Conway, Pisoni, \& Kronenberger, 2009), which holds that exposure to sound, given its temporal and sequential nature, provides a scaffolding for learning how to process sequential information. Auditory deprivation early in life would then affect the development of domain-general cognitive sequencing capacities, which are necessary for acquiring spoken language, because they allow to extract structural regularities from the linguistic input (Conway et al., 2009, p. 277). Such an account raises the question of whether CHI's language skills can be improved by enhancing general cognitive abilities such as sequencing and statistical learning. Bedoin et al. (2018) observed that $\mathrm{CHI}$ with $\mathrm{Cls}$ showed improvement in a grammaticality judgement task and in a non-word repetition task after sessions of morphosyntactic training with musical primes, but not after training sessions where the primes were environmental sounds without rhythmic structure. However, this difference was not observed in a syntax comprehension task in which the participants were required to follow instructions to execute actions; in this case, performance improved after training with 
both rhythmic and non-rhythmic primes. Although there is evidence supporting the auditory scaffolding hypothesis, there is also evidence inconsistent with it (see Deocampo, Smith, Kronenberger, Pisoni, and Conway, 2018 for a review). Furthermore, the direction of the relationship between language and cognitive sequencing in development is also under debate, and it has been proposed that poor sequencing abilities might not cause but be caused by poor language development (language scaffolding hypothesis, Hall, Eigsti, Bortfeld, and Lillo-Martin, 2018). Further research is needed to shed light on the link between language and sequencing abilities in development, as well as on the potential of cognitive training for improving spoken language skills in $\mathrm{CHI}$.

Given the wide variability present in $\mathrm{CHI}$, neither of these accounts can explain all cases of morphosyntactic difficulties in $\mathrm{CHI}$ on its own. For example, not all $\mathrm{CHI}$ who show morphosyntactic difficulties fail to perceive less salient grammatical markers (Ruigendijk and Friedmann, 2017; Schouwenaars et al., 2019), and some studies have failed to find correlations between measures of short-term memory and working memory capacity, and performance in sentence comprehension and production (Volpato, 2010; Penke and Wimmer, 2018). Most likely, all of the phenomena described by these accounts are relevant factors, and just how relevant each of them is differs from one case to another, depending on the interplay with other factors.

Besides how the morphosyntactic difficulties in $\mathrm{CHI}$ can be explained, it is also a matter of debate whether these difficulties are indicative of a persistent deficit or of a delay in linguistic development. Proponents of the persistent deficit hypothesis argue that evidence of CHI's difficulties in adolescence suggests that language does not generally normalize with age (Delage and Tuller, 2007; Friedmann and Haddad-Hanna, 2014). However, longitudinal studies on sentence comprehension and production that would allow to clarify this issue are extremely rare. Delage (2008), also reported in Tuller and Delage (2014), analyzed the spontaneous speech of a group of $\mathrm{CHI}$ with mild to moderate $\mathrm{HL}$ at ages $6 ; 1-11 ; 11$ and then again at ages $7 ; 11-13 ; 11$. They found that only the youngest children (mean age of 8 at first testing and of 10 at second testing) showed improvements in mean length of utterance and rate of embedding, while the eldest children (mean age of 11 at first testing and of 13 at second testing) stagnated and still performed below a group of 11-year-old TDC. Opposite to this finding, Penke and Wimmer (2018) assessed who-question comprehension in a group of $\mathrm{CHI}$ with mild to severe $\mathrm{HL}$ aged 3-4 years, and then again in a subset of those $\mathrm{CHI}$ when they were 6-8 years. While at age 3-4 the $\mathrm{CHI}$ performed significantly below age-matched CTD, at age 6-8 they performed at ceiling. 
As has been pointed out by Penke and Wimmer (2018, p. 14), more longitudinal studies testing a variety of syntactic structures and, we might add, a wider age range, are needed to help settle the debate whether CHI's difficulties evince a persistent deficit or a delay.

\section{Conclusions}

In this work we have reviewed the evidence on how children with prelingual hearing loss who use spoken language comprehend and produce sentences, focusing on simple sentences, topicalized sentences, passives, sentences with relative clauses, and wh-questions. We have also gone over factors that introduce heterogeneity in the population of $\mathrm{CHI}$ and revised the evidence on how their performance with specific sentence structures relates to demographic, clinical and cognitive variables. Finally, we have summarised different accounts that have tried to explain the morphosyntactic difficulties that characterise this population.

Studies have shown overall good performance with simple, active sentences with canonical word order. In contrast, $\mathrm{CHI}$ display visible difficulties with more complex sentences, specially with topicalization, relative clauses and wh-questions. More studies are necessary to determine whether passive sentences are also generally problematic. We encourage future research on CHI's language development to expand the range of languages and structures tested, while considering the specificities of each language and analyzing performance in each type of structure separately. This will help pinpoint the difficulties experienced by $\mathrm{CHI}$, which will in turn improve therapeutic and educational practices.

Better comprehension and production of complex sentences has been related to earlier intervention and longer use of hearing devices, as well as to higher short-term memory and working memory capacity. While the relation with many other variables has been assessed, the results are not convergent. What is clear, however, is that the heterogeneity characteristic of the $\mathrm{CHI}$ population must be considered carefully, and that sources of heterogeneity need to be attended. We recommend carrying out individual analyses along with group analyses.

This literature review reveals two areas of research that need further development. First, studies of online processing of sentences in $\mathrm{CHI}$ are very scarce. We believe these are necessary to obtain a deeper understanding of how $\mathrm{CHI}$ acquire and process spoken language, the time-course of morphosyntactic cues retrieval and its relation to other domain-general capac- 
ities like working memory capacity, planning and self-monitoring. Second, longitudinal studies assessing how sentence comprehension and production evolve as $\mathrm{CHI}$ grow up are also very rare. This might be partly due to the fact that modern hearing devices are relatively recent. We expect that, as early hearing loss detection programs become more frequent worldwide and more children with $\mathrm{HL}$ access modern hearing devices and therapy, it will be easier to conduct longitudinal studies. This kind of studies will hopefully shed light on the development of CHI's morphosyntactic difficulties.

\section{References}

Bedoin, N., Besombes, A.-M., Escande, E., Dumont, A., Lalitte, P., \& Tillmann, B. (2018). Boosting syntax training with temporally regular musical primes in children with cochlear implants. Annals of Physical and Rehabilitation Medicine, 61(6), 365-371. doi:10.1016/j. rehab.2017.03.004

Bishop, D. V. M. (2003). Test for reception of grammar (trog-2) (2nd ed.). San Antonio, TX: The Psychological Corporation.

Boons, T., de Raeve, L., Langereis, M., Peeraer, L., Wouters, J., \& van Wieringen, A. (2013). Expressive vocabulary, morphology, syntax and narrative skills in profoundly deaf children after early cochlear implantation. Research in Developmental Disabilities, 34(6), 20082022. doi:10.1016/j.ridd.2013.03.003

Briscoe, J., Bishop, D. V. M., \& Norbury, C. F. (2001). Phonological processing, language, and literacy: A comparison of children with mild-to-moderate sensorineural hearing loss and those with specific language impairment. Journal of Child Psychology and Psychiatry and Allied Disciplines, 42(3), 329-340. doi:10.1017/S0021963001007041

Caselli, M. C., Rinaldi, P., Varuzza, C., Giuliani, A., \& Burdod, S. (2012). Cochlear implant in the second year of life: Lexical and grammatical outcomes. Journal of Speech, Language, and Hearing Research, 55, 382-394. doi:10.1044/1092-4388(2011/10-0248)

Conway, C. M., Pisoni, D. B., \& Kronenberger, W. G. (2009). The importance of sound for cognitive sequencing abilities. the auditory scaffolding hypothesis. Current Directions in Psychological Science, 18(5), 275-279. doi:10.1111/j.1467-8721.2009.01651.x 
Costa, J. \& Moita, M. (2016). Movimento xO em crianças com implante coclear: Evidência para défice sintático em casos de input tardio. Revista da Associação Portuguesa de Linguística, 2, 205-234. doi:10.21747/2183-9077/rapl2a9

Dammeyer, J. (2010). Psychosocial development in a Danish population of children with cochlear implants and deaf and hard-of-hearing children. Journal of Deaf Studies and Deaf Education, 15(1), 50-58. doi:10.1093/deafed/enp024

Davis, J. \& Blasdell, R. (1975). Perceptual strategies employed by normal-hearing and hearingimpaired children in the comprehension of sentences containing relative clauses. Journal of Speech and Hearing Research, 18(2), 281-295. doi:10.1044/jshr.1802.281

de Villiers, P. A. (1988). Assessing English syntax in hearing-impaired children: Elicited production in pragmatically motivated situations. Journal of the Academy of Rehabilitative Audiology, 21(Mono Suppl), 41-71.

Delage, H. (2008). Evolution de l'hétérogénéité linguistique chez les enfants sourds légers et moyens: Etude de la complexité syntaxique (Doctoral dissertation, François-Rabelais University, Tours).

Delage, H. \& Tuller, L. (2007). Language development and mild-to-moderate hearing loss: Does language normalize with age? Journal of Speech, Language, and Hearing Research, 50, 1300-1313. doi:10.1044/1092-4388(2007/091)

DeLuca, Z. W. (2015). Wh-question processing in children with cochlear implants (Doctoral dissertation, City University of New York, New York). Retrieved from https:/ /academicworks. cuny.edu/gc_etds/902

Deocampo, J. A., Smith, G. N. L., Kronenberger, W. G., Pisoni, D. B., \& Conway, C. M. (2018). The role of statistical learning in understanding and treating spoken language outcomes in deaf children with cochlear implants. Language, Speech, and Hearing Services in Schools, 49, 723-739. doi:10.1044/2018_LSHSS-STLT1-17-0138

Dillon, C. M., Cleary, M., Pisoni, D. B., \& Carter, A. K. (2004). Imitation of nonwords by hearingimpaired children with cochlear implants: Segmental analyses. Clinical Linguistics \& Phonetics, 18(1), 39-55. doi:10.1080/0269920031000151669

D'Ortenzio, S. \& Volpato, F. (2020). How do Italian-speaking children handle wh-questions? a comparison between children with hearing loss and children with normal hearing. Clinical Linguistics \& Phonetics, 34(4), 407-429. doi:10.1080/02699206.2019.1677779 
Duchesne, L., Sutton, A., \& Bergeron, F. (2009). Language achievement in children who received cochlear implants between 1 and 2 years of age: Group trends and individual patterns. Journal of Deaf Studies and Deaf Education, 14(4), 465-485. doi:10.1093/deafed/ enp010

Friedmann, N. \& Costa, J. (2011). Last resort and no resort: Resumptive pronouns in Hebrew and Palestinian Arabic hearing impairment. In A. Rouveret (Ed.), Resumptive pronouns at the interfaces (pp. 223-239). John Benjamins. doi:10.1075/lfab.5

Friedmann, N. \& Haddad-Hanna, M. (2014). The comprehension of sentences derived by syntactic movement in Palestinian Arabic-speaking children with hearing impairment. Applied Psycholinguistics, 35(3), 473-513. doi:10.1017/S0142716412000483

Friedmann, N., Novogrodsky, R., Szterman, R., \& Preminger, O. (2008). Resumptive pronouns as last resort when movement is impaired: Relative clauses in hearing impairment. In S. Armon-Lotem, S. Rothstein, \& G. Danon (Eds.), Current issues in generative hebrew linguistics (pp. 276-290). Amsterdam, The Netherlands: John Benjamins. doi:10.1075/ la.134.11res

Friedmann, N., Rizzi, L., \& Belletti, A. (2016). No case for case in locality: Case does not help interpretation when intervention blocks a-bar chains. Glossa: a journal of general linguistics, 2(1), 33. doi:10.5334/gjgl.165

Friedmann, N. \& Szterman, R. (2006). Syntactic movement in orally-trained children with hearing impairment. Journal of Deaf Studies and Deaf Education, 11, 56-75. doi:10.1093/ deafed/enj002

Friedmann, N. \& Szterman, R. (2011). The comprehension and production of wh-questions in deaf and hard-of-hearing children. Journal of Deaf Studies and Deaf Education, 16(2), 212-235. doi:10.1093/deafed/ENQ052

Fujiyoshi, A., Fukushima, K., Taguchi, T., Omori, K., Kasai, N., Nishio, S., .. Shiroma, M. (2012). Syntactic development in Japanese hearing-impaired children. Annals of Otology, Rhinology \& Laryngology, 121(4), 28-34. doi:10.1177/000348941212100404

Geers, A. E., Moog, J. S., Biedenstein, J., Brenner, C., \& Hayes, H. (2009). Spoken language scores of children using cochlear implants compared to hearing age-mates at school entry. Journal of Deaf Studies and Deaf Education, 14(3), 371-385. doi:10.1093/deafed/ enn046 
Geers, A. E., Nicholas, J. G., \& Sedey, A. L. (2003). Language skills of children with early cochlear implantation. Ear and Hearing, 24, 46S-58S. doi:10.1097/01.AUD.0000051689.57380. $1 \mathrm{~B}$

Gillis, S. (2018). Speech and language in congenitally deaf children with a cochlear implant. In A. Bar-On \& D. Ravid (Eds.), Handbook of communications disorders: Theoretical, empirical, and applied linguistic perspectives (pp. 765-792). Berlin: De Gruyter Mouton. doi:10 . 1515/9781614514909-038

Guasti, M. T., Papagno, C., Vernice, M., Cecchetto, C., Giuliani, A., \& Burdo, S. (2014). The effect of language structure on linguistic strengths and weaknesses in children with cochlear implants: Evidence from Italian. Applied Psycholinguistics, 35, 739-764. doi:10 .1017/ S0142716412000562

Guo, L.-Y., Spencer, L. J., \& Tomblin, B. (2013). Acquisition of tense marking in English-speaking children with cochlear implants: A longitudinal study. Journal of Deaf Studies and Deaf Education, 18(2), 187-205. doi:10.1093/deafed/ens069

Hall, M. L., Eigsti, I.-M., Bortfeld, H., \& Lillo-Martin, D. (2018). Auditory access, language access, and implicit sequence learning in deaf children. Developmental Science, 21(3), e12575. doi:10.1111/desc. 12575

Halliday, L. F. \& Bishop, D. V. M. (2005). Frequency discrimination and literacy skills in children with mild to moderate sensorineural hearing loss. Journal of Speech, Language, and Hearing Research, 48, 1187-1203. doi:10.1044/1092-4388(2005/083)

Halliday, L. F., Tuomainen, O., \& Rosen, S. (2017). Language development and impairment in children with mild to moderate sensorineural hearing loss. Journal of Speech, Language, and Hearing Research, 60, 1551-1567. doi:10.1044/2016_JSLHR-L-16-0297

Hammer, A. (2010). The acquisition of verbal morphology in coclear-implanted and specific language impaired children (Doctoral dissertation, Faculteit der Letteren, Leiden University). Retrieved from https://www .lotpublications.nl/the-acquisition-of-verbalmorphology-in-cochlear-implanted-and-specifi-the-acquisition-of-verbal-morphologyin-cochlear-implanted-and-specific-language-impaired-children

Hansson, K., Forsberg, J., Löfqvist, A., Mäki-Torkko, E., \& Sahlén, B. (2004). Working memory and novel word learning in children with hearing impairment and children with specific language impairment. International Journal of Language \& Communication Disorders, 39(3), 401-422. doi:10.1080/13682820410001669887 
Harris, M. S., Kronenberger, W. G., Gao, S., Hoen, H. M., Miyamoto, R. T., \& Pisoni, D. B. (2013). Verbal short-term memory development and spoken language outcomes in deaf children with cochlear implants. Ear and Hearing, 34(2), 179-192. doi:10.1097/AUD.0b013e318269ce50

Inscoe, J. R., Odell, A., Archbold, S., \& Nikolopoulos, T. (2009). Expressive spoken language development in deaf children with cochlear implants who are beginning formal education. Deafness \& Education International, 11(1), 39-55. doi:10.1002/dei.252

Kidd, E. \& Donnelly, S. (2020). Individual differences in first language acquisition. Annual Review of Linguistics, 6(1), 319-340. doi:10.1146/annurev-linguistics-011619-030326

Kitzinger, M. \& John, J. (1980). Hearing-impaired children's understanding of active, passive and scrambled sentences. In I. G. Taylor \& A. Markides (Eds.), Disorders of auditory function (Vol. 3, pp. 73-78). Academic Press.

Koehlinger, K. M., Horne, A. J. O. V., \& Moeller, M. P. (2013). Grammatical outcomes of 3- and 6-year-old children who are hard of hearing. Journal of Speech, Language, and Hearing Research, 56(5), 1701-1714. doi:10.1044/1092-4388(2013/12-0188)

Le Normand, M.-T., Ouellet, C., \& Cohen, H. (2003). Productivity of lexical categories in Frenchspeaking children with cochlear implants. Brain and Cognition, 53(2), 257-262. doi:10. 1016/S0278-2626(03)00122-2

Lee, Y., Sung, J. E., \& Sim, H. (2018). Passive sentence comprehension difficulties and its related factors in children with cochlear implants. International Journal of Pediatric Otorhinolaryngology, 109, 60-66. doi:10.1016/j.ijporl.2018.03.02

Lenneberg, E. H. (1967). Biological foundations of language. New York: Wiley.

Mandal, J. C., Kumar, S., \& Roy, S. (2016). Comparison of auditory comprehension skills in children with cochlear implant and typically developing children. International Journal of Pediatric Otorhinolaryngology, 91, 113-120. doi:10.1016/j.ijporl.2016.10.009

Moita, M. \& Lobo, M. (2018). Compreensão e produção oral de interrogativas-q em crianças portuguesas surdas com implante coclear. Revista da Associação Portuguesa de Linguística, 4, 168-189. doi:10.26334/2183-9077/rapln4ano2018a39

Nikolopoulos, T. P., Dyar, D., Archbold, S., \& O’Donoghue, G. M. (2004). Development of spoken language grammar following cochlear implantation in prelingually deaf children. Archives of Otolaryngology - Head and Neck Surgery, 130(5), 629-633. doi:10.1001/ archotol.130.5.629 
Niparko, J. K., Tobey, E. A., Thal, D. J., Eisenberg, L. S., Wang, N.-Y., Quittner, A. L., \& Fink, N. E. (2010). Spoken language development in children following cochlear implantation. Journal of the American Medical Association, 303(15), 1498-1506. doi:10.1001/jama.2010. 451

Nittrouer, S., Sansom, E., Low, K., Rice, C., \& Caldwell-Tarr, A. (2014). Language structures used by kindergartners with cochlear implants: Relationship to phonological awareness, lexical knowledge and hearing loss. Ear and Hearing, 35(5), 506-518. doi:10.1097/AUD. 0000000000000051

Norbury, C. F., Bishop, D. V. M., \& Briscoe, J. (2001). Production of English finite verb morphology: A comparison of sli and mild-moderate hearing impairment. Journal of Speech, Language, and Hearing Research, 44, 165-178. doi:1092-4388/01/4401-0165

Norbury, C. F., Bishop, D. V. M., \& Briscoe, J. (2002). Does impaired grammatical comprehension provide evidence for an innate grammar module? Applied Psycholinguistics, 23, 247-268. doi:10.1017.S0142716402002059

Novogrodsky, R., Meir, N., \& Michael, R. (2018). Morphosyntactic abilities of toddlers with hearing impairment and normal hearing: Evidence from a sentence-repetition task. International Journal of Language \& Communication Disorders, 53(4), 811-824. doi:10.1111/ $1460-6984.12386$

Penke, M. \& Wimmer, E. (2018). Deficits in comprehending wh-questions in children with hearing loss - the contribution of phonological short-term memory and syntactic complexity. Clinical Linguistics \& Phonetics, 32(3), 267-284. doi:10.1080/02699206.2017.1350883

Pisoni, D. D. \& Geers, A. E. (2000). Working memory in deaf children with cochlear implants: Correlations between digit span and measures of spoken language processing. Annals of Otology, Rhinology, and Laryngology, 185, 92-93. doi:10.1177/0003489400109s1240

Power, D. J. \& Quigley, S. P. (1973). Deaf children's acquisition of the passive voice. Journal of Speech and Hearing Research, 16, 5-11.

Qi, S. \& Mitchell, R. E. (2012). Large-scale academic achievement testing of deaf and hard-ofhearing students: Past, present, and future. Journal of Deaf Studies and Deaf Education, 17(1), 1-18. doi:10.1093/deafed/enr028

Quigley, S. P., Smith, N. L., \& Wilbur, R. B. (1974). Comprehension of relativized sentences by deaf students. Journal of Speech and Hearing Research, 17, 325-341. doi:10.1044/jshr. 1703.325 
Quigley, S. P., Wilbur, R. B., \& Montanelli, D. S. (1974). Question formation in the language of deaf students. Journal of Speech and Hearing Research, 17, 699-713. doi:10.1044/jshr. 1704.699

Reynell, J. K. \& Gruber, C. P. (1990). Reynell developmental language scales. Los Angeles, CA: Western Psychological Services.

Ruigendijk, E. \& Friedmann, N. (2017). A deficit in movement-derived sentences in Germanspeaking hearing-impaired children. Frontiers in Psychology, 8, 689. doi:10.3389/fpsyg. 2017.00689

Schorr, E. A., Roth, F. P., \& Fox, N. A. (2008). A comparison of the speech and language skills of children with cochlear implants and children with normal hearing. Communication Disorders Quarterly, 29(4), 195-210. doi:10.1177/1525740108321217

Schouwenaars, A., Finke, M., Hendriks, P., \& Ruigendijk, E. (2019). Which questions do children with cochlear implants understand? an eye-tracking study. Journal of Speech, Language, and Hearing Research, 62, 387-409. doi:10.1044/2018_JSLHR-H-17-031

Semel, E., Wiig, E., \& Secord, W. (1995). Clinical evaluation of language fundamentals-iii. San Antonio, TX: Psychological Corporation.

Semel-Mintz, E., Wiig, E., \& Secord, W. (2003). Clinical evaluation of language fundamentals (4th ed). San Antonio, TX: Psychological Corporation.

Soleymani, Z., Mahmoodabadi, N., \& Nouri, M. M. (2016). Language skills and phonological awareness in children with cochlear implants and normal hearing. International Journal of Pediatric Otorhinolaryngology, 83, 16-21. doi:10.1016/j.ijporl.2016.01.013

Sundström, S., Löfkvist, U., Lyxell, B., \& Samuelsson, C. (2018). Phonological and grammatical production in children with developmental language disorder and children with hearing impairment. Child Language Teaching and Therapy, 34(3), 289-302. doi:10.1177/ 0265659018805202

Svirsky, M. A., Stallings, L. M., Lento, C. L., Ying, E., \& Leonard, L. B. (2002). Grammatical morphologic development in pediatric cochlear implant users may be affected by the perceptual prominence of the relevant markers. The Annals of Otology, Rhinology \& Laryngology. Supplement, 189, 109-112.

Szagun, G. (2000). The acquisition of grammatical and lexical structures in children with cochlear implants: A developmental psycholinguistic approach. Audiology and Neurotology, 5(1), 39-47. doi:10.1159/000013864 
Szagun, G. (2004). Learning by ear: On the acquisition of case and gender marking by Germanspeaking children with cochlear implants and with normal hearing. Journal of Child Language, 31, 1-30. doi:10.1017/S0305000903005889

Teymouri, R., Daneshmandan, N., Hemmati, S., \& Soleimani, F. (2014). Perception development of complex syntactic construction in children with hearing impairment. Iranian Rehabilitation Journal, 12(22), 11-16. Retrieved from http: / / irj . uswr . ac . ir / article-1-426en.html

Tomblin, J. B., Barker, B. A., Spencer, L. J., Zhang, X., \& Gantz, B. J. (2005). The effect of age at cochlear implant initial stimulation on expressive language growth in infants and toddlers. Journal of Speech, Language, and Hearing Research, 48(4), 853-867. doi:10.1044/ $1092-4388(2005 / 059)$

Tomblin, J. B., Harrison, M., Ambrose, S. E., Walker, E. A., Oleson, J. J., \& Moeller, M. P. (2015). Language outcomes in young children with mild to severe hearing loss. Ear and Hearing, 36, 76S-91S. doi:10.1097/AUD.0000000000000219

Tuller, L. \& Delage, H. (2014). Mild-to-moderate hearing loss and language impairment: How are they linked? Lingua, 139, 80-101. doi:10.1016/j.lingua.2013.10.009

Volpato, F. (2010). The acquisition of relative clauses and phi-features in hearing and hearingimpaired populations (Doctoral dissertation, Ca' Foscari University of Venice). Retrieved from http://dspace.unive.it/handle/10579/1024

Volpato, F. (2020). Verbal working memory resources and comprehension of relative clauses in children with cochlear implants. First Language, 1-21. doi:10.1177/0142723719900739

Volpato, F. \& D'Ortenzio, S. (2018). Ask a question! how Italian children with cochlear implants produce subject and object wh-questions. Bucharest Working Papers in Linguistics, 20(2), 53-76.

Volpato, F. \& Vernice, M. (2014). The production of relative clauses by Italian cochlear-implanted and hearing children. Lingua, 139, 39-67. doi:10.1016/j.lingua.2013.10.010

Werfel, K. L. (2018). Morphosyntax production of preschool children with hearing loss: An evaluation of the extended optional infinitive and surface accounts. Journal of Speech Language and Hearing Research, 61(9), 2313. doi:10.1044/2018_jslhr-l-17-0406

Werfel, K. L., Reynolds, G., Hudgins, S., Castaldo, M., \& Lund, E. A. (2021). The production of complex syntax in spontaneous language by 4-year-old children with hearing loss. Ameri- 
can Journal of Speech-Language Pathology, 30(2), 609-621.doi:10.1044/2020_AJSLP20-00178

Wimmer, E., Rothweiler, M., \& Penke, M. (2017). Acquisition of who-question comprehension in German children with hearing loss. Journal of Communication Disorders, 67, 35-48. doi:10.1016/j.jcomdis.2017.05.003

Woolfolk-Carrow, E. (1999). Test for auditory comprehension of language. Austin, TX: Pro-ed.

Young, G. A. \& Killen, D. H. (2002). Receptive and expressive language skills of children with five years of experience using a cochlear implant. Annals of Otology, Rhinology \& Laryngology, 111, 802-810. doi:10.1177/000348940211100908 


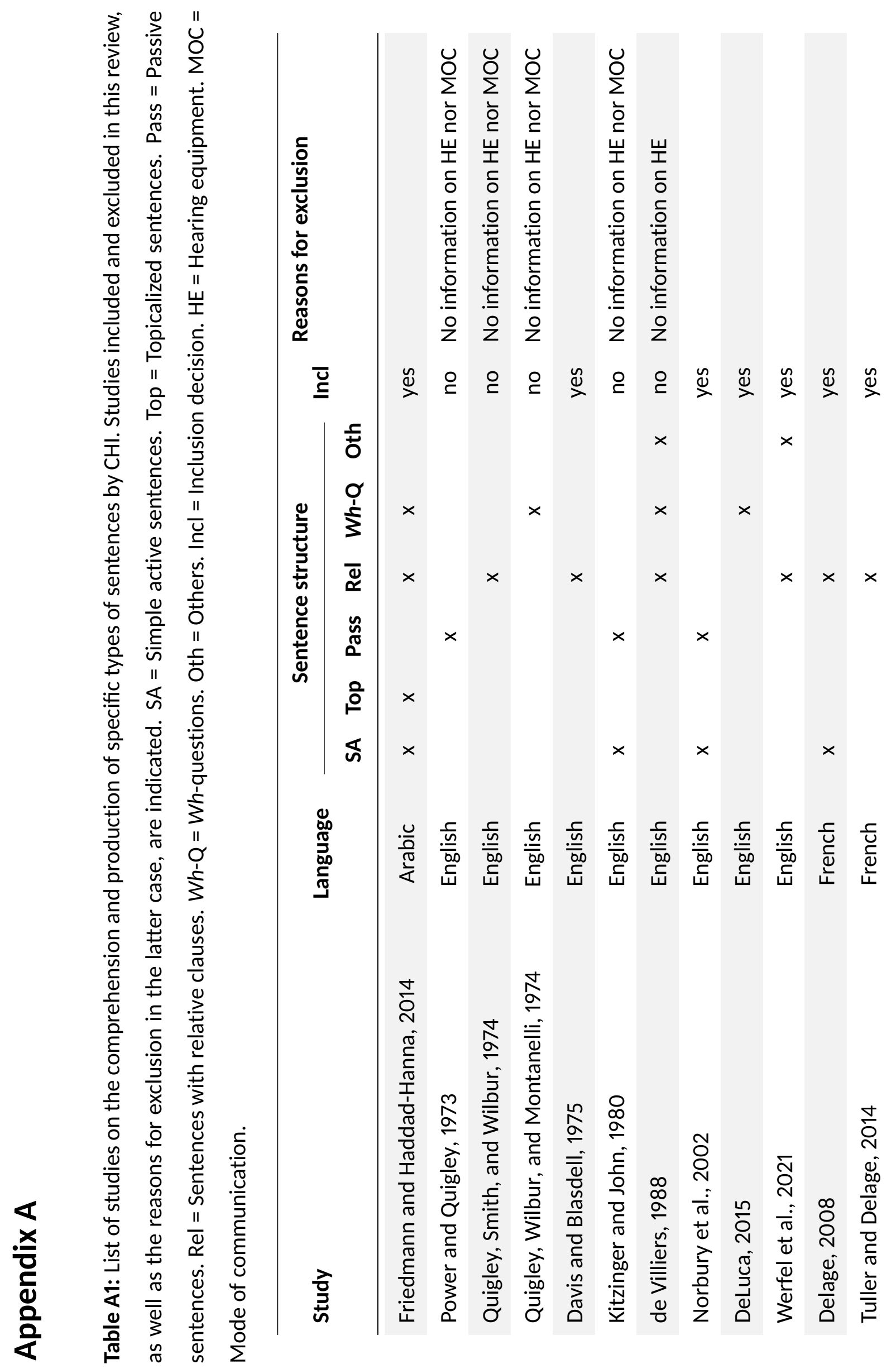




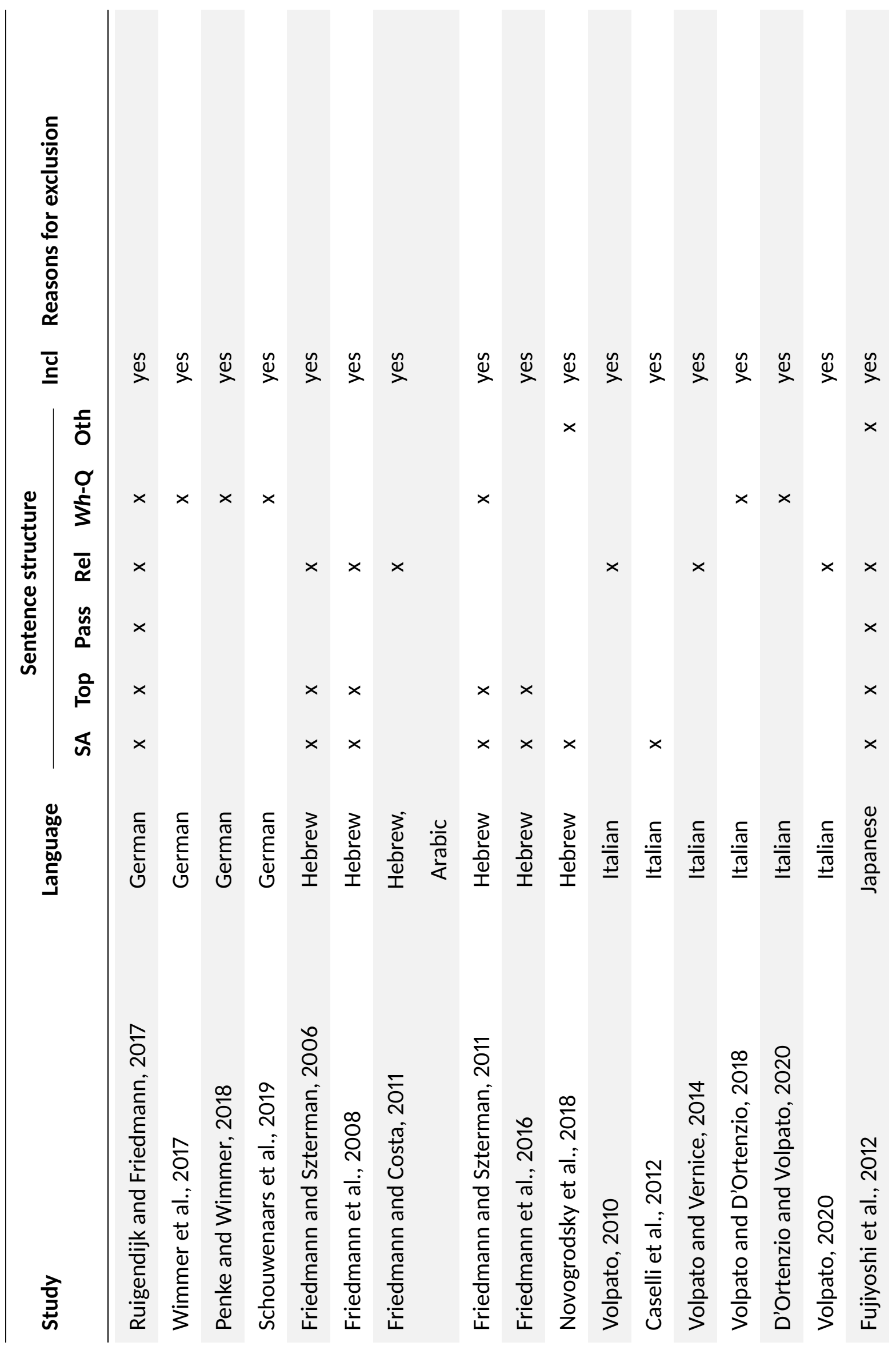




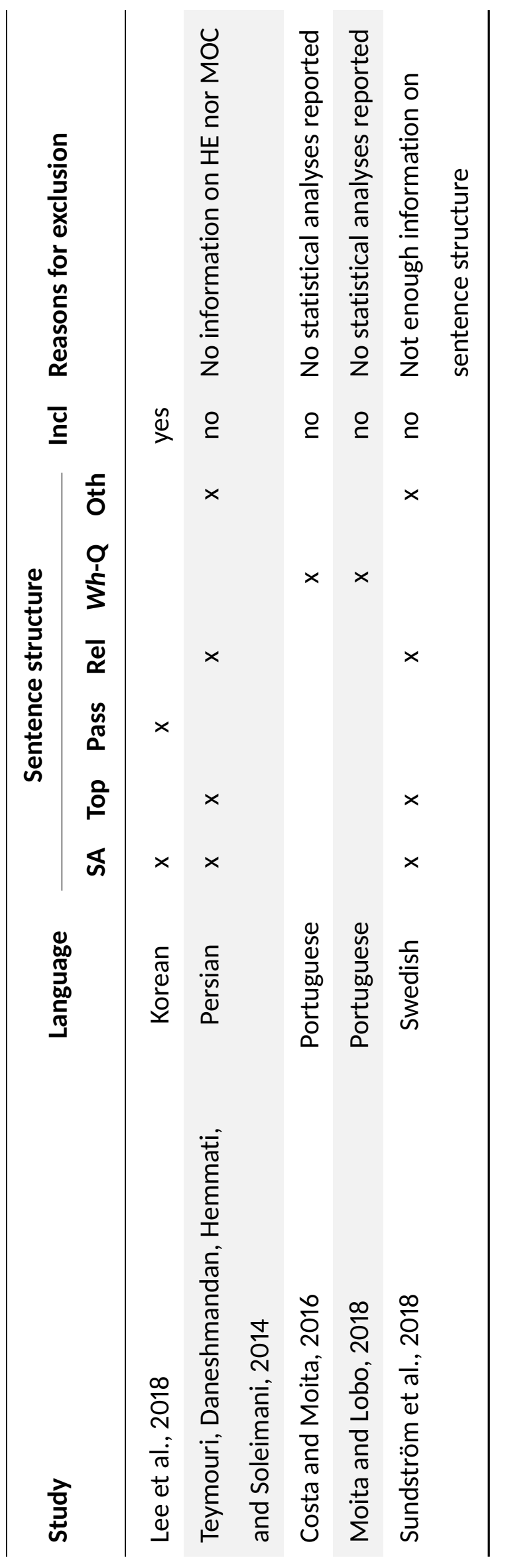




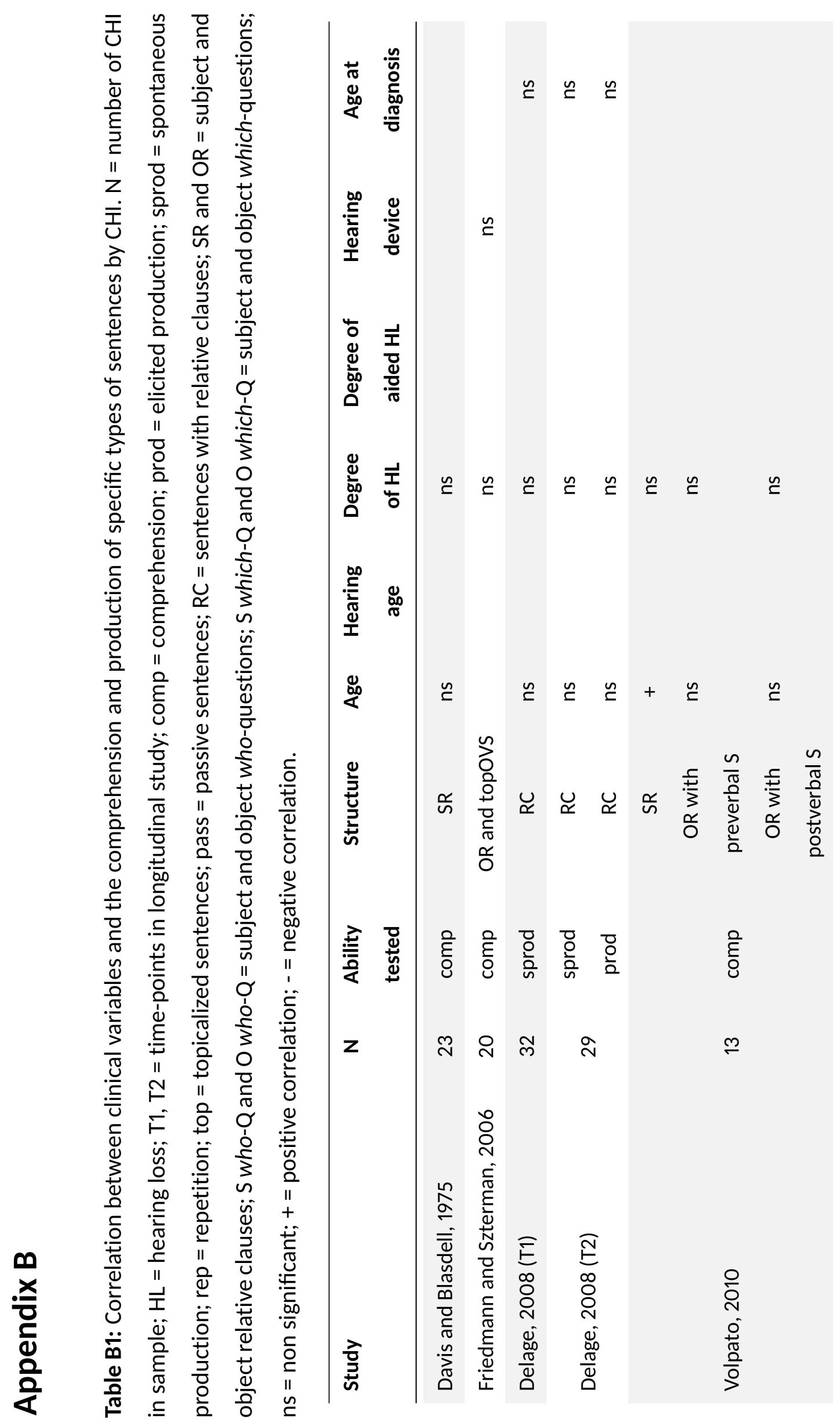




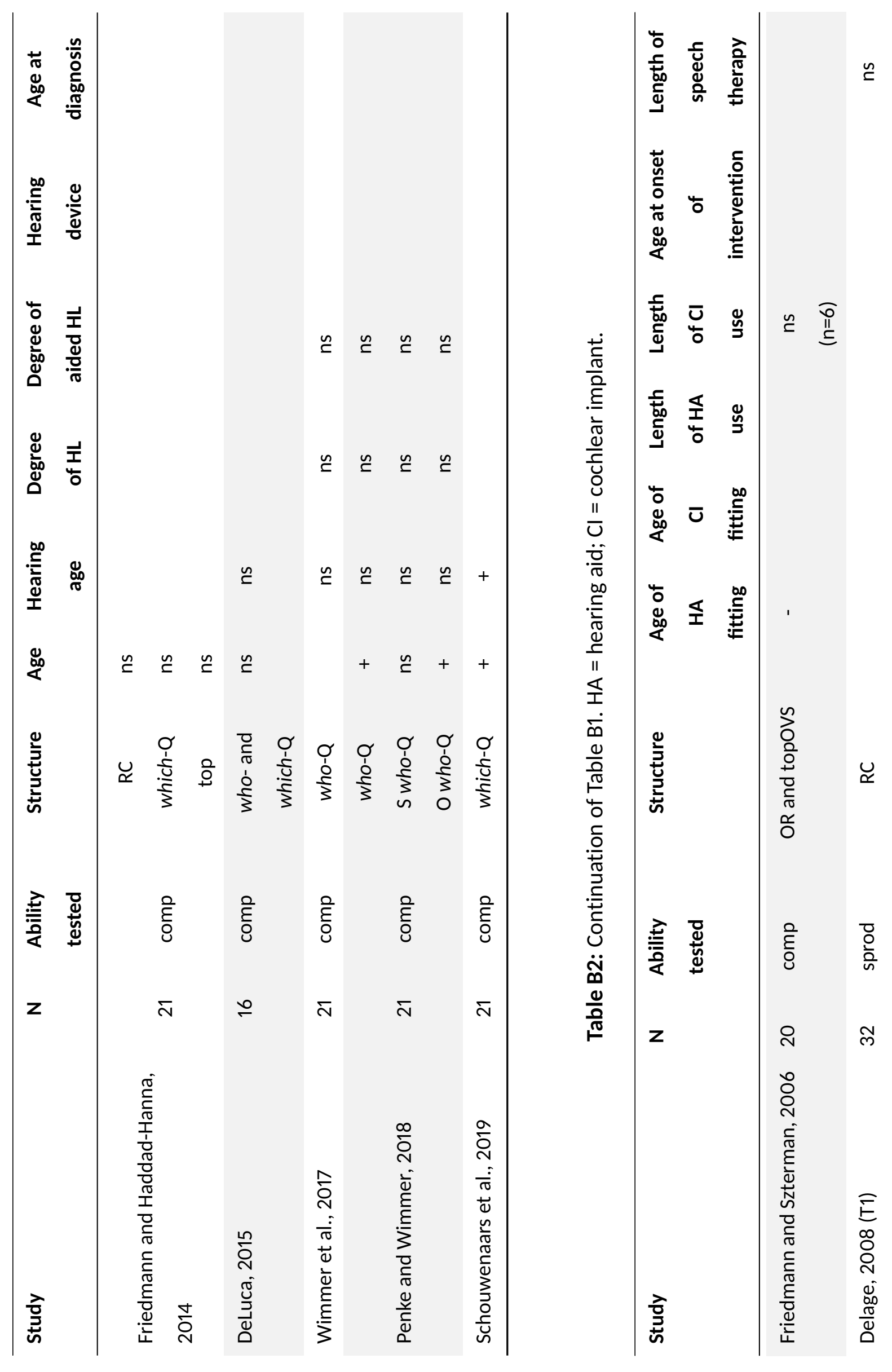




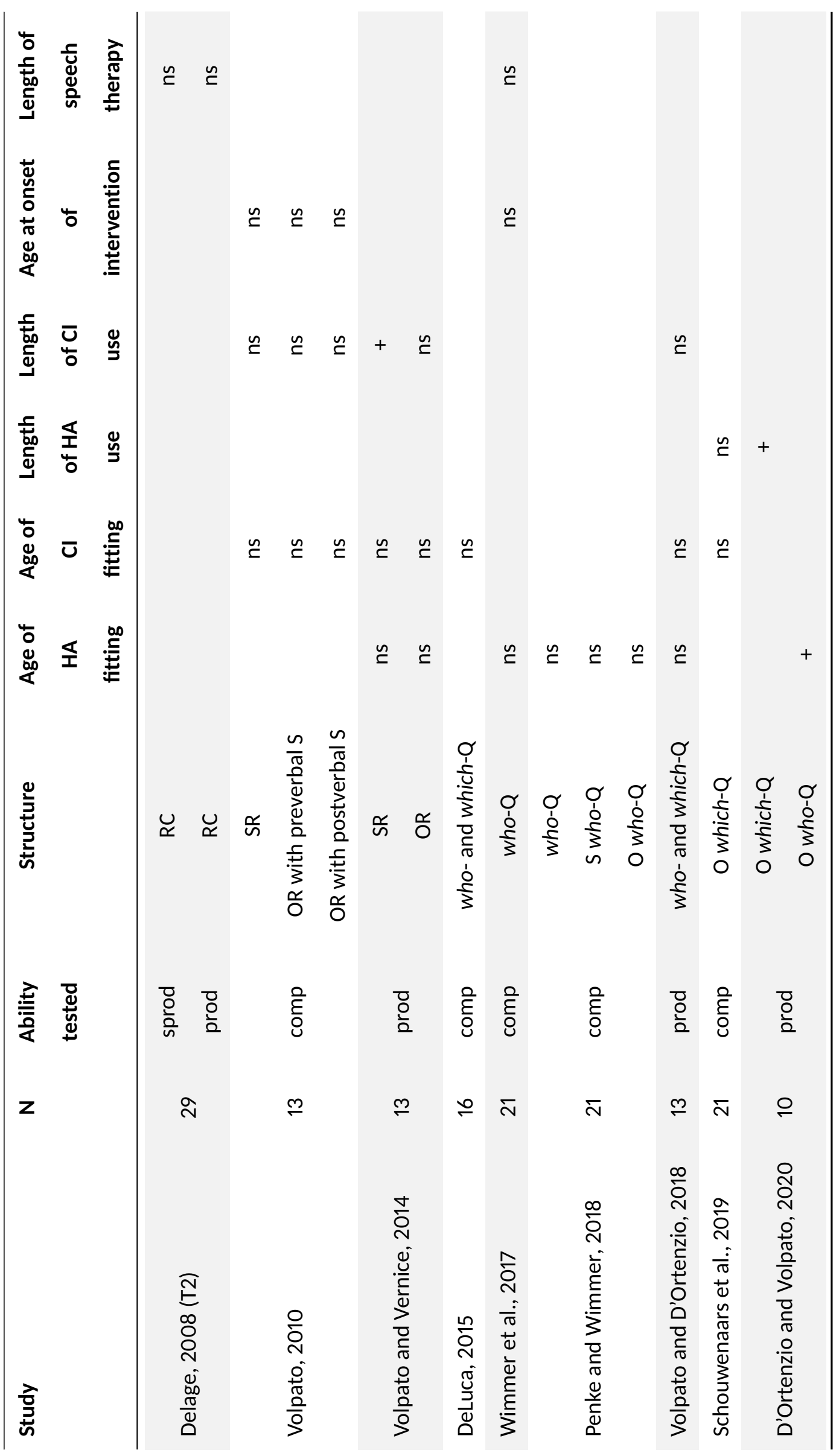




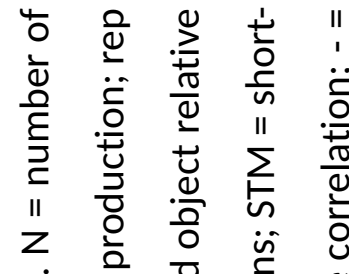

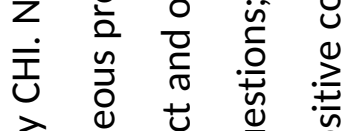

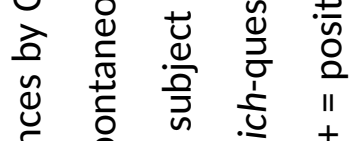

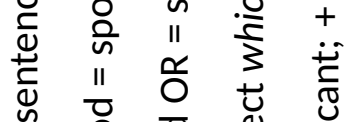

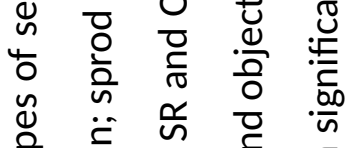

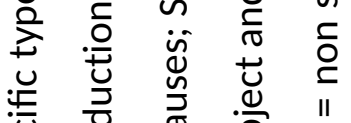

啳

¿

亮

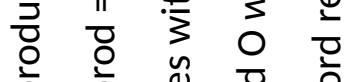

立

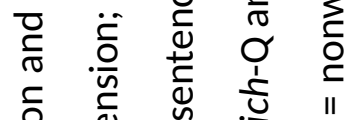

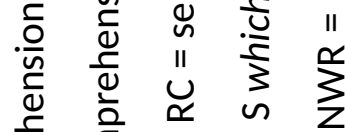

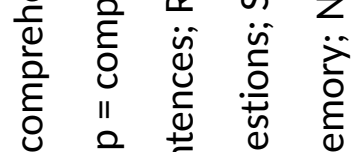

岂

苛

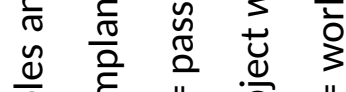

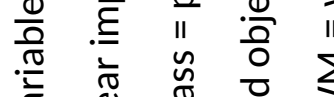

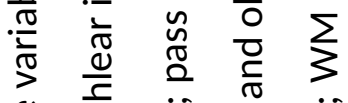

:

总

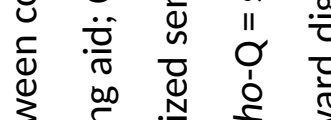

䓛

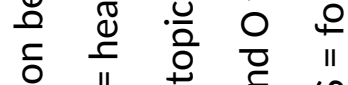

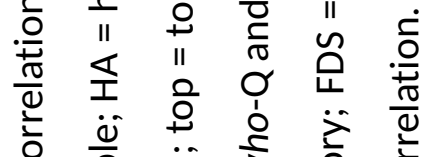

立

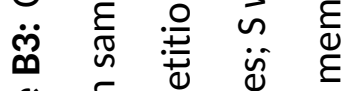

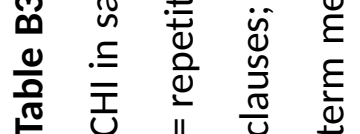

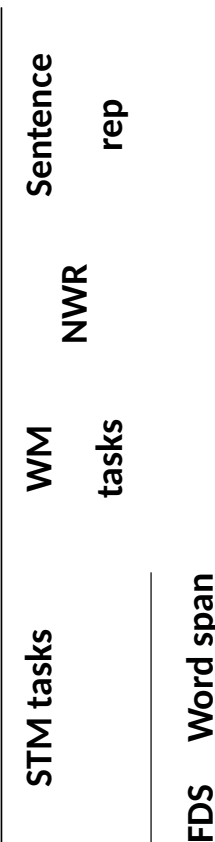

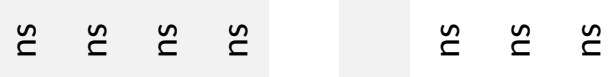

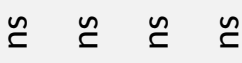

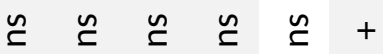

$+\stackrel{\complement}{\check{c}}$

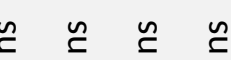

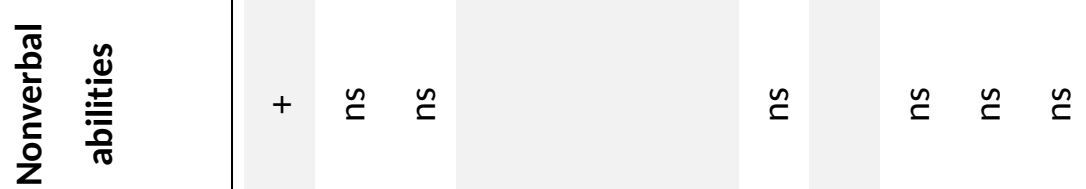

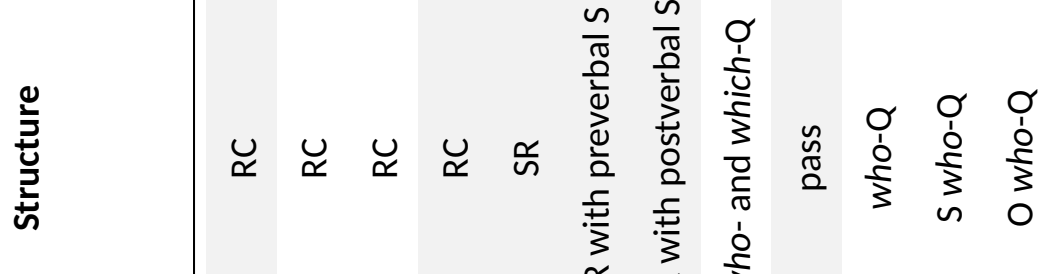

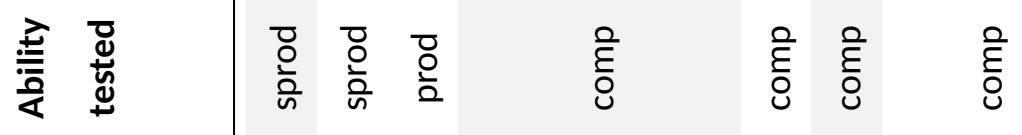

z

言

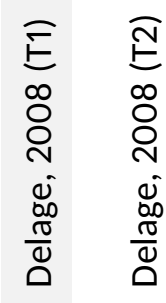

0
ㄱ.
0
$\frac{0}{0}$
$\frac{0}{0}$

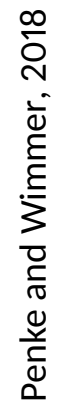




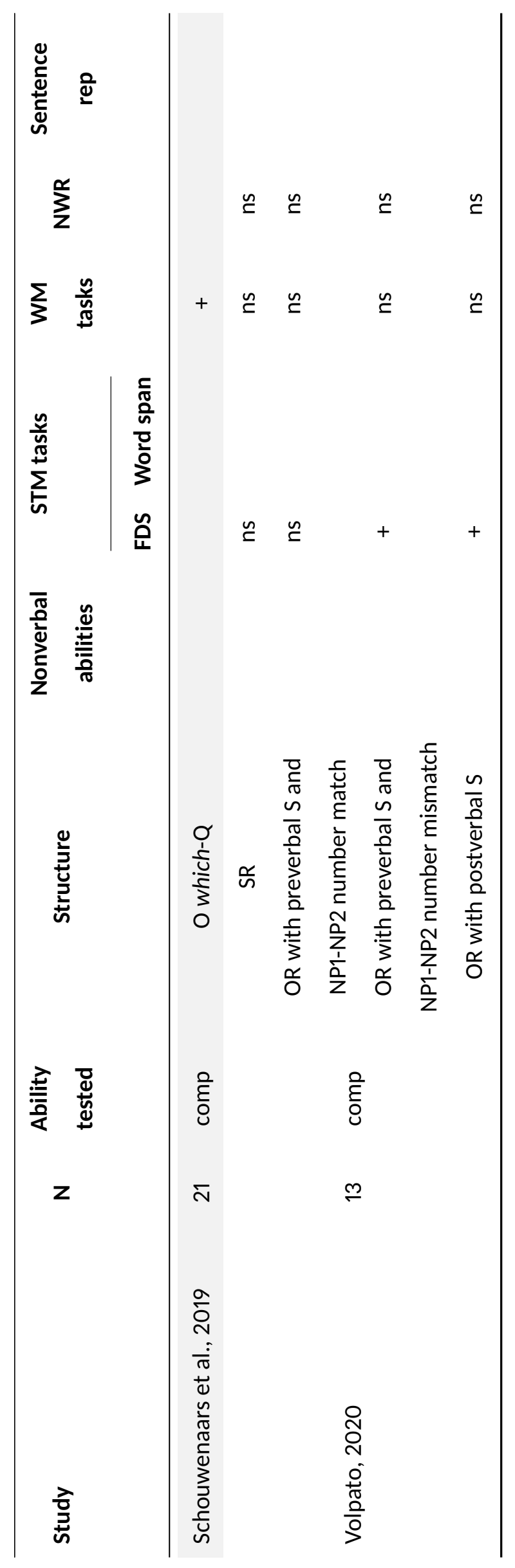

